\title{
Consenso colombiano de expertos sobre recomendaciones informadas en la evidencia para la prevención, el diagnóstico y el manejo de la infección por SARS-CoV-2/COVID-19 en pacientes con Enfermedad Renal Crónica en diálisis Colombian Expert Consensus on Evidence-Informed Recommendations for the Prevention, Diagnosis, and Management of SARS-CoV-2 / COVID-19 Infection in Patients with Chronic Kidney Disease on Dialysis
}

๑ Nancy Yomayusa González ${ }^{1,2}$, ${ }^{\circ}$ Erika Yama ${ }^{1,2,3}$, ${ }^{\bullet}$ Camilo González ${ }^{1,3}$, Amaury Ariza ${ }^{1,4},{ }^{\oplus}$ Gustavo Aroca ${ }^{1,5}$, ${ }^{\oplus}$ Richard Baquero ${ }^{6,7},{ }^{\oplus}$ Jorge Rico ${ }^{1,8}, \odot$ Juan Guillermo Vargas ${ }^{1}$, Roberto Ramírez ${ }^{1}{ }^{\oplus}$ Kelly Chacón $^{2},{ }^{\oplus}$ Adriana Robayo ${ }^{1}$, ${ }^{\oplus}$ Adalberto Peña Wilches ${ }^{1,9},{ }^{\oplus}$ Adriana Meza ${ }^{6,10},{ }^{\oplus}$ Alfonso Bunch ${ }^{1,11},{ }^{\odot}$ Álvaro Mercado ${ }^{1,12}$, ${ }^{\oplus}$ Angélica Calderón ${ }^{6,13}$,

Benjamín Wancjer ${ }^{1}$, Betty Zambrano, Carlos Lozano ${ }^{1},{ }^{\oplus}$ Cristóbal Buitrago ${ }^{14},{ }^{\oplus}$ David Ballesteros ${ }^{1,15}$, ๑ Diana Chacón ${ }^{6,16}$, Diana Vargas ${ }^{1,}{ }^{\oplus}$ Douglas Villafañe ${ }^{6,17}$, Francisco López ${ }^{1}$, Freddy Pinzón ${ }^{1,11},{ }^{\oplus}$ Gustavo Guerrero ${ }^{6,18}$,

${ }^{\odot}$ Héctor Cárdenas ${ }^{1,3},{ }^{\oplus}$ Helman Benavides ${ }^{1},{ }^{\oplus}$ Ignacio Villanueva $^{1,12}$, Ingrid Raoch ${ }^{1},{ }^{\oplus}$ Jimena Cáceres $^{3,6}$,

๑Jorge Coronado ${ }^{1},{ }^{\oplus} J_{0}$ orge Pulido ${ }^{1},{ }^{\odot}$ Kateir Contreras $^{19}$, Luis Alfonso Valderrama Cometa ${ }^{1}$, María Gómez ${ }^{1}$,

๑ María José Vargas Brochero ${ }^{20}$,๑ Martha Carrasca ${ }^{16,21},{ }^{\oplus}$ Martha Rodríguez $^{22}$, Mauricio Guerrero ${ }^{1}$,

${ }^{\oplus}$ Mercedes Alfaro Tejeda ${ }^{1,23}$, Natalia Tobón ${ }^{1}$, Paula Rodríguez ${ }^{1},{ }^{\oplus}$ Rafael Gómez ${ }^{1,11},{ }^{\oplus}$ Rodrigo Daza ${ }^{1,8}$, Rodolfo Torres ${ }^{1},{ }^{\circledR}$ Zilac Espitaleta ${ }^{5,6}$, Álvaro Burgos ${ }^{24}$

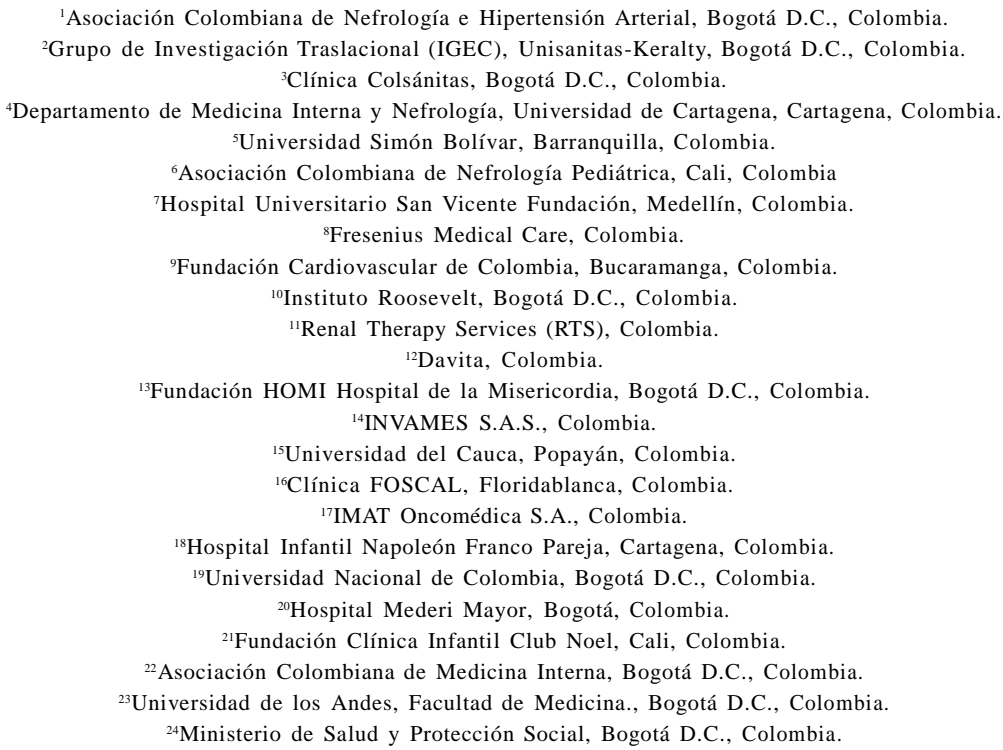

Citación: Yomayusa N, Yama E, González C, Ariza A, Aroca G, Baquero R, et al. Consenso colombiano de expertos sobre recomendaciones informadas en la evidencia para la prevención, el diagnóstico y el manejo de infección por SARS-CoV-2/COVID-19 en pacientes con enfermedad renal. Crónica en diálisis. Rev. Colomb. Nefrol. 2020;7(Supl. 2):118-158. https://doi.org/10.22265/acnef.7.Supl.2.474 Correspondencia: Nancy Yomayusa González,nyomayusa@colsanitas.com Recibido: 02.06 .20 - Aceptado: $02.06 .20 \cdot$ Publicado en línea: 02.06 .20

118 Consenso colombiano de expertos sobre recomendaciones informadas en la evidencia para... 


\begin{abstract}
Resumen
Introducción: Las personas con diálisis de mantenimiento se consideran una población en alto riesgo de infección por SARS-CoV2, complicaciones y muerte. La periodicidad de la diálisis, la organización y la demanda en las unidades de diálisis y las limitaciones de alfabetización en salud poblacional limitan el cumplimiento del aislamiento y el distanciamiento social.
\end{abstract}

Objetivo: Desarrollar, mediante un consenso de expertos, recomendaciones informadas en evidencia para la prevención, el diagnóstico y el manejo de la infección por SARS-CoV-2/COVID-19 en pacientes con enfermedad renal crónica.

Materiales y métodos: Se realizó una revisión rápida de literatura en Pubmed, Embase y sociedades científicas. La calidad de evidencia fue evaluada según el tipo de estudio incluido. El acuerdo se definió para cada recomendación con umbral de al menos $70 \%$ de aprobación. La fuerza de las recomendaciones fue graduada como fuerte o débil.

Resultados: El colectivo fue consultado entre el 17 y 19 de mayo de 2020. Se obtuvo respuesta de 44 expertos clínicos que declararon conflicto de interés previo a la consulta. El acuerdo de las recomendaciones estuvo entre 70,5 y 100\%. Se presentan las recomendaciones de un colectivo experto para la prevención, el diagnóstico y el manejo de infección por SARS-CoV-2/COVID-19 en pacientes con enfermedad renal crónica.

Conclusión: Debido a la reciente aparición de la infección por SARS-CoV-2 y las incertidumbres respecto a la prevención, el diagnóstico y el manejo, las recomendaciones presentadas se conciben como un estándar colombiano que permita garantizar un cuidado centrado en las personas con enfermedad renal crónica y la protección de los profesionales de la salud.

Palabras clave: SARS-CoV-2, COVID-19, insuficiencia renal crónica, diálisis renal.

https://doi.org/10.22265/acnef.7.Supl.2.474

\begin{abstract}
Introduction: People with chronic dialysis are considered a population at high risk of SARS CoV2 infection and its derived complications and death. The need to go to strict dialysis schedules, the high demand in the kidney facilities and the difficulties derived from the time and space organization in the rooms in the face to the pandemic added to the difficult learning, teaching and adapting new protocols manifest the needed of standard recommendation according to this problem in people who couldn't have an ideal isolation.

Objective: Develop through an expert consensus, evidence-informed recommendations for the prevention, diagnosis, and management of SARS-CoV-2/COVID-19 infection in patients with chronic kidney disease on Dialysis.

Materials and methods: We carried out a quick literature review, PubMed, Embase and scientific societies were consulted. The quality of the evidence was considered according to the type of study included. The agreement threshold defined for each recommendation was $>70 \%$ approval among experts. The strength of the recommendations was rated as strong or weak.

Results: Between May 17 and 19, 2020, was conformed a team of 44 clinical experts who declared their interest conflict prior to the consultation. The agreement of the recommendations was between $70.5 \%$ and $100 \%$. The recommendations were separated in prevention, early identification, and diagnostic, isolation in hemodialysis facilities and peritoneal dialysis, and team protection. Ethical considerations also were included.

Conclusion: Due to the recent appearance of SARS-CoV-2 infection and the uncertainties regarding prevention, diagnosis and management, the recommendations presented are conceived as a Colombian standard that allows guaranteeing focused care for people with chronic kidney disease and the protection of health team.

Key words: SARS-CoV-2, COVID-19, chronic kidney disease, hemodialysis.
\end{abstract}

https://doi.org/10.22265/acnef.7.Supl.2.474

\section{Introducción}

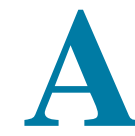

finales de 2019 el mundo conoció una nueva enfermedad producida por el coronavirus SARS-CoV-2 que inició en Wuhan (China), que luego se diseminó en los cinco continentes y fue declarada como pandemia por la OMS el 11 marzo de 2020. Rápidamente se mostró la gravedad de la enfermedad, pues llevó al colapso de los sistemas de salud en las comunidades china, europea y norteamericana; en efecto, para principios de mayo de 2020 se habían reportado más de 3,5 millones de casos y 250.000 fallecidos ${ }^{1}$. De las características clínicas y las formas de presentación se ha identifi- cado que la enfermedad es más grave en adultos mayores de 60 años y con patologías crónicas como diabetes e hipertensión ${ }^{2}$. Es así como la población con enfermedad renal crónica (ERC) en sus diferentes estadios constituye una combinación de varias patologías y condiciones de mayor riesgo.

En Colombia, la ERC es una condición de muy frecuente presentación; se estima que aproximadamente un $10 \%$ de la población tiene algún grado de enfermedad renal ${ }^{3}$. En el último informe de la Cuenta de Alto Costo había 3120 casos de enfermedad renal en niños y por encima de 40.000 personas en estadio 5 o con requerimiento de terapia remplazo renal (TRR), de las 
cuales el 59\% se encontraba en hemodiálisis, el $22 \%$ en diálisis peritoneal y el $18 \%$ trasplantados. Cerca de un $56 \%$ de la población en diálisis es mayor de 60 años. Por lo tanto, no se deben escatimar esfuerzos en definir medidas de protección, cuidado y atención en este grupo de pacientes ${ }^{4}$.

Los pacientes con ERC en estadio 5 dependientes de hemodiálisis no pueden cumplir las cuarentenas y aislamientos, viéndose obligados a asistir a su terapia de remplazo renal tres veces a la semana; por otro lado, la misma enfermedad condiciona un estado de inmunosupresión, algunas veces sumado a desnutrición y además las dos principales etiologías de la enfermedad renal crónica (hipertensión arterial y diabetes mellitus) son igualmente condicionantes de riesgo de gravedad en COVID-19. Los reportes epidemiológicos en países donde se ha presentado la enfermedad en forma masiva sugieren un comportamiento clínico diferencial respecto a Wuhan, donde no hubo mayores diferencias a la población general, vs. Italia y Estados Unidos, donde se demarca mayor necesidad de terapias intensivas y hospitalización ${ }^{5,6}$.

En el marco de referencia de prevención y diagnóstico y manejo de la COVID-19 para el país propuesto por ACIN no se profundizó en los aspectos relevantes de la población adulta y pediátrica con enfermedad renal crónica en todo su espectro ${ }^{7}$, por lo cual, y dado el impacto que supone en carga de enfermedad e implicaciones para las personas que la padecen y para el sistema de salud colombiano, desde la Asociación Colombiana de Nefrología e Hipertensión Arterial $^{8}$ y la Asociación Colombiana de Nefrología Pediátrica (Aconepe), asumimos la responsabilidad de desarrollar recomendaciones informadas en evidencia sobre la prevención, el diagnóstico y el manejo de la infección por SARS-CoV-2 o enfermedad de COVID-19 en pacientes con enfermedad renal crónica (ERC), como estrategia para gestionar el riesgo al que se ven expuestos nuestros pacientes y trabajadores de la salud.

\section{Objetivo general}

Generar, mediante un consenso de expertos en nefrología, recomendaciones informadas en eviden- cia disponible para orientar la toma de decisiones en prevención, diagnóstico y manejo de infección por SARS-CoV-2 o enfermedad COVID-19, logrando así un estándar colombiano que permita garantizar un cuidado centrado en las personas con enfermedad renal crónica y la protección de los profesionales de la salud.

\section{Metodología}

El grupo desarrollador definió las preguntas y categorías de interés, priorizando cinco condiciones específicas:
a. Hemodiálisis
b. Lesión renal aguda asociada a COVID-19
c. ERC en pediatría
d. Adultos mayores multimórbidos
e. Trasplante renal

Cada una de las condiciones se realizó a través de la metodología que se expone a continuación; sin embargo, su desarrollo se dio de manera independiente y cada una es presentada en capítulos diferentes. En este capítulo se presentarán las recomendaciones para pacientes con ERC en diálisis.

\section{Revisión rápida de literatura: hemodiálisis}

El abordaje de las preguntas se realizó a través de revisión rápida de literatura. Los hallazgos se presentan considerando aspectos del manual de resumen de evidencia del Joanna Briggs Institute 9.

- Fuentes de información: Se realizó consulta en sociedades científicas, sitios oficiales de desarrolladores de guías de práctica clínica (GPC) y bases de datos Pubmed, Embase.

- Estrategia de búsqueda: Términos MesH, Emtree, texto libre incluyendo términos: renal disease, kidney disease, SARS-CoV-2, COVID.

o Pubmed:

Search $(((($ dialysis [Title/Abstract]) OR Renal Replacement Therapy)) AND ((kidney disease [Title/Abstract]) OR renal disease))) 
AND $(((((($ covid [Title/Abstract]) $)$ OR coronavirus[Title/Abstract]) OR sars cov 2 [Title/Abstract]) OR sars-cov-2[Title/ Abstract])) AND ((kidney disease [Title/ Abstract]) OR renal disease))

o Embase:

\#1'kidney disease':ab,ti OR 'chronic kidney failure':ab,ti OR dialysis:ab,ti

\#2 coronavirus:ab,ti OR covid:ab,ti OR 'sars $\operatorname{cov} 2^{\prime}: \mathrm{ab}, \mathrm{ti}$

\section{\#1 AND \#2}

- Tipo de estudios: Se incluyeron GPC, comunicados, reportes técnicos, revisiones sistemáticas, ensayos clínicos, estudios observacionales, series de casos, reportes de casos, considerando la pertinencia para resolver las preguntas.

- Tamización, selección y extracción de evidencia: Se realizó por la coordinación metodológica.

- Evaluación de calidad: La calidad de los estudios fue realizada por la coordinación metodológica, aplicando las herramientas AGREE II para guías de práctica clínica, AMSTAR-2 para revisiones sistemáticas y meta-análisis, RoB para ensayos clínicos, New Castle Otawa para estudios observacionales (cohortes o casos y controles) y herramienta Joanna Briggs Institute para series de casos o reportes de caso. Los resultados se presen$\tan$ en el anexo A.

\section{Recomendaciones preliminares}

A partir de la evidencia recolectada, el comité coordinador de hemodiálisis y la coordinación metodológica formulan las recomendaciones preliminares adaptadas al contexto nacional.

\section{Consenso con expertos Delphi modificado}

Teniendo en cuenta la coyuntura de la pandemia y con el objetivo de involucrar a la mayor cantidad de especialistas en nefrología del país y de otras disciplinas relacionadas, el comité directivo y metodológico divulgó las recomendaciones preliminares a un grupo de expertos clínicos de representación nacional.

El colectivo fue consultado entre el 17 y 19 de mayo de 2020, a través de una herramienta en línea, acerca de su posición (acuerdo, desacuerdo) frente a cada recomendación preliminar y tuvo la oportunidad de presentar observaciones y justificar el desacuerdo. Para cada recomendación se estimó el porcentaje de acuerdo, siendo el numerador el número de personas que expresaron esta postura y el denominador, el total de personas que respondieron a dicha recomendación.

Se definió acuerdo para la recomendación cuando se obtuvo $70 \%$ o más de aprobación por parte de respondedores de la herramienta. Para las recomendaciones que no alcanzaran acuerdo se planeó su discusión en una sesión de consenso; sin embargo, para la condición de pacientes con ERC en diálisis todas las recomendaciones preliminares divulgadas y consultadas superaron el umbral y no hubo necesidad de pasar a sesión virtual de consenso. Los resultados se presentan en el anexo B.

El colectivo experto declaró el conflicto de interés mediante el diligenciamiento del formato diseñado para este fin. Para el análisis de la consulta se tuvo en cuenta 44 expertos clínicos, que enviaron su declaración de conflicto de interés. Además, el comité metodológico analizó el conflicto declarado y su potencial efecto en las respuestas emitidas para garantizar la transparencia del consenso.

\section{Clasificación de la recomendación}

Finalizado el proceso de consulta y consenso (cuando aplicó), se procedió a la elaboración del documento final y a la clasificación de la fuerza de la recomendación por parte del comité directivo y metodológico en dos categorías: Fuerte y Débil. Se consideró la calidad de evidencia, el balance de riesgos-beneficios, el consumo de recursos o disponibilidad en el contexto y las observaciones emitidas por el colectivo experto. 
- Fuerte: Los clínicos deberían implementar la acción en la mayor parte de los pacientes.

- Débil: Los clínicos deberían reconocer que hay diferentes opciones apropiadas para distintos pacientes $\mathrm{y}$, en este caso, habría que ayudar a cada paciente a alcanzar la decisión más consistente con sus valores y preferencias.

\section{Revisión del documento final}

El grupo desarrollador divulgó el documento final para revisión por parte del colectivo experto.

\section{Contexto epidemiológico}

Al 02 de mayo de 2020, la enfermedad por COVID19 ha sido diagnosticada en cerca de 3,4 millones de personas en el mundo con 240.000 muertes. Los países con mayor número de casos confirmados se ubican en Norteamérica y Europa, específicamente Estados Unidos (33\%), España e Italia (6\% cada uno), Reino Unido y Francia (5\% cada uno) ${ }^{3}$. En Colombia hasta el 01 de mayo se confirmaron 7006 casos y 314 muertes (Minsalud). Si bien los datos de Colombia vienen en crecimiento, aún estamos en momento de tomar medidas de gestión para evitar el potencial impacto de lo que podría ser la pandemia en nuestro contexto y lo que podría significar para nuestros pacientes con enfermedad renal crónica.

En Colombia, se estima que cerca de un $10 \%$ de la población tiene algún grado de enfermedad renal. En el año 2018 se reportaron 3120 casos en población pediátrica y más de 40.000 personas en estadio 5 (TRR), de las cuales 59\% se encontraban en hemodiálisis, $22 \%$ en diálisis peritoneal y $18 \%$ trasplantados. Cerca de un $56 \%$ de la población en diálisis es mayor de 60 años 5 .

En razón de la pandemia, esta distribución de pacientes podría verse afectada, por disminución de trasplantes que implicarían un incremento en la demanda de diálisis en centros especializados. Además, según indica Burgner, los pacientes con insuficiencia renal en diálisis de mantenimiento con sospecha o confirmación de infecciones con COVID-19 están siendo enviados a hospitales, lo que aumentará el número de pacientes hospitalizados en diálisis ${ }^{10}$.

En el contexto de la enfermedad renal crónica, el riesgo de infección con COVID-19 y su impacto requiere mayor profundización y estudio ${ }^{6,11}$, y son escasos los lineamientos de manejo en esta condición específicamente ${ }^{12}$. Al respecto, la información disponible es principalmente basada en reporte de experiencias de unidades renales.

En el Centro Universitario Baskent, en Turquía, se ha reportado un caso por cada 1000 pacientes de diálisis ${ }^{13}$; en el centro de Nefrología y Diálisis Italiana el $16 \%$ de los pacientes en hemodiálisis se contagiaron con SARS-CoV-2 ${ }^{14}$, el mismo porcentaje reportado por mortalidad en estos pacientes del $87 \%$, aunque las causas de la muerte aparentemente no estaban relacionadas con la neumonía ${ }^{11}$.

La experiencia de una unidad en el norte de Italia reportó que el $83 \%$ de pacientes con TRR tenían COVID-19. El 75\% estaba en hemodiálisis, el 3\% en diálisis peritoneal, el $20 \%$ fueron pacientes trasplantados y el $1 \%$ estaban en espera de trasplante. La prevalencia de positividad de SARS-CoV-2 en pacientes de esta con TRR en esta unidad fue mayor respecto a la población general, en alrededor de 13 veces (OR 13,43, IC del 95\%: 11,27 a 16,00; $p<0,0001)^{15}$.

En China se reportó que el $4,3 \%$ de pacientes COVID-19 graves tenían ERC ${ }^{16}$. En el meta- análisis de Michael con datos preliminares, se encontró asociación de ERC con COVID-19 grave (OR 3,03, IC $95 \% 1,09-8,47$, I $2=0,0 \%)^{17}$. La comorbilidad ha sido asociada con la gravedad de COVID-19. En pacientes con ERC se ha identificado comorbilidad con diabetes, cardiopatía e hipertensión ${ }^{11,18,19}$.

Finalmente, el personal de salud de las unidades renales o de hemodiálisis tiene un alto riesgo de contagio. En el Hospital Renmin de la Universidad de Wuhan, el 12\% del personal de salud de unidad de hemodiálisis tuvo COVID-19 ${ }^{11}$; y en la unidad en el norte de Italia, el 17\%. Según el reporte de Manganaro, el personal de salud tiene cerca de 13 veces la posibilidad para positividad de SARS-CoV-2 respecto a la población general (OR 12,80, IC del 95\% 8,67 a 18,89 p < 0,0001) ${ }^{15}$.

122 Consenso colombiano de expertos sobre recomendaciones informadas en la evidencia para... 


\section{Prevención}

La naturaleza de la enfermedad COVID-19 y su rápida y fácil trasmisión reafirma la necesidad de implementar medidas de cuidado en la práctica cotidiana. La prevención siempre será la medida de mayor costo-efectividad; por lo tanto, diferentes estrategias son requeridas en unidades renales y de diálisis, donde el flujo de pacientes es continuo, dada la dificultad de suspender sus servicios: «la diálisis es un procedimiento que salva vidas y la pérdida del procedimiento podría tener impacto negativo en la vida de los pacientes $»^{20}$.

Por consiguiente, las medidas deben ser extremadas para evitar el contagio de pacientes y del personal de salud.

El lavado de manos es considerado la estrategia universal de mayor efectividad de prevención de contagio de múltiples condiciones infectocontagiosas. El uso de elementos de protección personal (EPP) es una estrategia clave para evitar la propagación del virus desde la fuente y toma mayor importancia en la prevención del contagio de poblaciones altamente expuestas al virus como los son los profesionales de la salud; sin embargo, por alto riesgo de escasez en la pandemia su uso debe ser racional y adecuado. En efecto, los controles administrativos hacen parte de medidas globales, teniendo en cuenta la necesidad de garantizar y controlar la disponibilidad de recursos tanto de personal en salud, como de insumos para la prestación de los servicios; además, son requeridos ajustes de capacidad instalada, habilitación de unidades aisladas, redistribución de estructura, por lo que medidas ambientales y de ingeniería son imprescindibles ${ }^{2}$.

\section{¿Qué medidas de bioseguridad se deben tener en cuenta en las unidades renales en los pacientes con diagnóstico confir- mado de COVID-19 y los pacientes en confirmación?}

Existe gran cantidad de información disponible relacionada con medidas de prevención en centros hospitalarios y unidades renales. Recomendaciones globales han sido publicadas por organizaciones mundialmente reconocidas para que instituciones particulares las implementen de acuerdo con sus propios contextos epidemiológicos y de disponibilidad de recursos ${ }^{21,22}$. Además, están disponibles recomendaciones dadas por expertos o por reportes de experiencia de unidades de diálisis.

Las medidas principalmente identificadas para implementar incluyen lavado de manos, comunicación y educación, uso de elementos de protección personal, tamización de pacientes y personal de la salud, clasificación de pacientes (sospechosos, contagiados), transporte seguro de pacientes, medidas de limpieza y desinfección e infraestructura y organización de unidades de diálisis. Además, el reforzamiento del aislamiento preventivo de familiares y pacientes y la vacunación anual contra la influenza de pacientes para evitar contagio por otros virus ${ }^{23}$.

\section{Comunicación y educación}

La implementación de estrategias de comunicación y educación parte de la idea de que las personas informadas toman mejores decisiones de cuidado personal y de los demás y, en consecuencia, actúan de manera prudente y adecuada. Estas estrategias se orientan a pacientes y personal de salud y de limpieza. La información a impartir incluye la enfermedad COVID-19, modo de propagación del virus SARS-CoV-2, identificación de síntomas, proceso de consulta en servicios de salud y unidad de diálisis, procesos de comunicación y contacto con la unidad de diálisis, medidas de prevención con énfasis en el correcto lavado de manos y uso adecuado de $\mathrm{EPP}^{8,21,24,25}$. El video podría ser una alternativa de capacitación rápida y eficiente ${ }^{26}$.

\section{Recomendaciones}

- Se recomienda que las unidades renales y de diálisis dispongan de carteleras y medios para informar a pacientes, familiares y personal de salud sobre COVID-19.

\section{Fuerte a favor}

- Se recomienda que los pacientes, los familiares, los visitantes y el personal de las unidades reci- 
ban información sobre la enfermedad COVID19 , la forma de contagio y los síntomas.

\section{Fuerte a favor}

- Se recomienda que la unidad divulgue información del lavado de manos respecto en cuanto a frecuencia y técnica correcta de realización.

\section{Fuerte a favor}

- Se recomienda que la unidad divulgue información acerca de la importancia del uso adecuado y racional de elementos de protección personal, específicamente del frecuente y correcto lavado de manos, el distanciamiento social y el uso de mascarillas para pacientes y familiares.

\section{Fuerte a favor}

- Se recomienda que los pacientes conozcan medios de contacto de la unidad renal, en caso en que requieran consultar información o notificar sintomatología antes de presentarse en la unidad.

\section{Fuerte a favor}

\section{Elementos de protección personal}

Durante la pandemia se pueden considerar los tapabocas o mascarillas quirúrgicas, guantes, respiradores N95, protectores oculares como caretas o monogafas, batas, delantal impermeable, gorro y botas o zapatos ${ }^{21,24}$. El Centro para el Control de Enfermedades (CDC) inicialmente recomendó el uso de respiradores N95, como es el procedimiento estándar en el cuidado de pacientes de alto riesgo. Sin embargo, en el entorno actual de infección viral pandémica, las máscaras faciales quirúrgicas estándar son aceptables si las máscaras N95 no están disponibles. Estos respiradores deben tener prioridad para los procedimientos que puedan generar aerosoles respiratorios. Teniendo en cuenta el alto riesgo de escasez de EPP durante la pandemia, la OMS y el CDC hacen un llamado a su uso racional y consistente ${ }^{21}$.

Los pacientes, los familiares y el responsable de traslados del paciente requerirán únicamente uso de mascarillas quirúrgicas, los demás EPP son para uso de personal de salud y de limpieza de acuerdo con la indicación de uso de cada uno ${ }^{24}$. Respecto al momento de uso de mascarilla por parte de los pacientes, algunos autores sugieren que para aquellos que no han confirmado o sospechado COVID-19 no deben usar máscaras durante el tratamiento, pero sí durante desplazamientos entre el hogar y el centro de diálisis, que a menudo es en una camioneta compartida con otros pacientes ${ }^{18}$; otros autores sugieren, además de este uso, que los pacientes lleven las mascarillas durante todo el tiempo que se encuentren en la unidad de diálisis ${ }^{12,21,24,25,27}$.

Dada la naturaleza del contagio, las particularidades de atención de las unidades de diálisis, en virtud de los patrones de periodicidad en dos a tres turnos día, con los requerimientos propios del cuidado de poblaciones de alto riesgo, en las cuales el aislamiento social y la cuarentena estricta no son viables de cumplir, aunado todo esto a las condiciones de inmunosupresión determinadas por la misma enfermedad, el envejecimiento, la multimorbilidad, el requerimiento de terapias, entre otros, se ha orientado la decisión de agencias internacionales para el uso del respirador N95 como estándar de protección personal, de acuerdo con la disponibilidad para la atención de pacientes con sospecha o confirmación de infección por SARS-CoV-2 y durante procedimientos que generen aerosoles ${ }^{8,21}$. Su disponibilidad podría verse comprometida, por lo que medidas de reutilización o prolongación de tiempo de uso están siendo revisadas. Mantener la máscara en un ambiente seco durante $3 a$ días asegura que el virus no se sobreponga, por lo que el suministro de respiradores N95 podría hacerse en ciclo de cuatro, uno para cada día, y luego reutilizar si las condiciones físicas del respirador son buenas ${ }^{28}$.

Las batas sugeridas deben ser impermeables o antifluido; cuando no se cumple este propósito, el uso de delantal es la opción para evitar el riesgo por salpicadura ${ }^{24,29}$. Además, las batas de aislamiento se recomiendan durante la conexión al acceso vascular, la conexión y la desconexión, ayudando al paciente dentro y fuera de la unidad o en la limpieza de la unidad ${ }^{21,29,30}$.

124 Consenso colombiano de expertos sobre recomendaciones informadas en la evidencia para... 
La efectividad de los EPP debe potenciarse con el lavado de manos y la disposición de desechos adecuada $^{21,24,29}$.

\section{Recomendaciones}

- Se recomienda que todos los pacientes y familiares usen mascarilla quirúrgica durante su estancia en la unidad.

\section{Fuerte a favor}

- No se recomienda el uso de tapabocas de tela para evitar propagación desde la fuente.

\section{Fuerte en contra}

- Se recomienda que el personal de salud use EPP para el desempeño seguro de sus funciones.

\section{Fuerte a favor}

- Se recomienda que el personal de salud de las unidades sea capacitado para el uso adecuado y racional de EPP.

\section{Fuerte a favor}

- Se recomienda que el personal de salud de las unidades use mascarilla quirúrgica durante su permanencia en la unidad.

\section{Fuerte a favor}

- Se recomienda que el personal dedicado a hemodiálisis use EPP de manera estricta: mascarilla quirúrgica, guantes, protectores oculares como caretas o monogafas y gorro, batas antifluido durante la conexión, la desconexión y la asistencia del paciente.

\section{Fuerte a favor}

- Se recomienda que el equipo involucrado en la atención directa de pacientes con sospecha o confirmación de COVID-19 utilice respirador N95 o nivel superior, de acuerdo con la disponibilidad del centro o unidad de diálisis. En tiempos de escasez, se debe optimizar la disponibilidad del recurso para situaciones donde la protección respiratoria es prioritaria, como en la realización de procedimientos con generación de aerosoles en pa- cientes con sospecha o confirmación de COVID-19.

\section{Fuerte a favor}

- Se recomienda que el personal de limpieza y desinfección use los EPP de acuerdo con la indicación de sus actividades.

\section{Fuerte a favor}

- Se recomienda que el uso de EPP se acompañe de higiene de manos.

\section{Fuerte a favor}

- Se recomienda que el personal de salud de las unidades participe en la generación de programas de educación, alfabetización en salud y comunicación efectiva sobre el uso adecuado y racional de EPP, utilizando diferentes didácticas a partir de los lineamientos informados en evidencia: videos, encuentros con expertos, simulacros, grupos focales, mentorías, videos, infografías, además de la implementación de sistemas de evaluación y seguimiento a la adherencia de las recomendaciones.

\section{Fuerte a favor}

- Se recomienda que los equipos de salud cumplan de manera estricta el lavado de manos según lo estipulado en los protocolos de bioseguridad, enfatizando los 5 momentos y los 10 pasos, durante 20 a 40 segundos, además del uso frecuente de alcohol gel.

\section{Fuerte a favor}

\section{Tamización para SARS-CoV-2/COVID-19}

La identificación oportuna de pacientes y personal con COVID-19 permite gestionar el riesgo dentro de las unidades renales, por lo que la Sociedad Internacional de Nefrología (ISN, por sus siglas en inglés) sugiere la implementación de protocolos de tamización para pacientes sospechosos de COVID19 y la priorización de tamización para el personal; además, invita a que pruebas RT-PCR sean aplicadas a todos los pacientes en diálisis ${ }^{29}$. Al respecto, la experiencia documentada del Policlínico de Milán sugiere que pacientes sintomáticos, antes de ingresar 
a la sala de diálisis, sean evaluados por el nefrólogo y el infectólogo a través de consulta remota para decidir si necesitan ser sometidos a la prueba diagnóstica $^{25}$. En la misma línea, NICE sugiere la prueba ante la sospecha y evaluar las causas alternativas de síntomas antes de la diálisis, cuando esto sea posible ${ }^{22}$.

\section{Recomendaciones}

- Se recomienda que el nefrólogo realice un análisis de riesgo-beneficio respecto a la tamización de los pacientes en diálisis; cada caso deberá ser evaluado de manera independiente.

\section{Fuerte a favor}

- Se recomienda que para pacientes sintomáticos y sospechosos se realice la prueba RTPCR antes de la diálisis; en el caso de diálisis peritoneal se recomienda tamizar pacientes y familiares sintomáticos.

\section{Fuerte a favor}

- Se recomienda que el personal de salud sintomático o involucrado en atención de pacientes sospechosos o confirmados nuevos se realice la prueba RT-PCR.

\section{Fuerte a favor}

\section{Triage o clasificación}

La clasificación de pacientes y de personal es una estrategia para gestionar el riesgo de contagio dentro de las unidades renales; la información disponible sugiere que debe existir un sistema de clasificación antes del ingreso de pacientes y que el personal de salud debe estar atento y capacitado para identificar pacientes sospechosos y surtir los procesos correspondientes ${ }^{8,12,21}$.

Algunas medidas recomendadas para la clasificación de pacientes incluyen la educación a pacientes para reportar a la unidad acerca de viajes o contactos con personas enfermas con COVID-1930, y la toma de temperatura antes y después del ingreso a las unidades ${ }^{29}$. En el documento de Meijers se define $38^{\circ} \mathrm{C}$ como umbral para remitir el paciente a urgencias $^{31}$. El triage telefónico o por mensaje de texto es otra opción disponible para el paciente que planea ir a la unidad; además, tener señalización en diferentes idiomas en sala de espera, preguntando a pacientes por requisitos de sospecha ${ }^{32}$.

En el triage se debe evaluar la presencia de síntomas (dificultad para respirar, tos, dolor de garganta y fiebre), si alguien en el hogar tiene síntomas, si alguien en el hogar tiene COVID-19 y si lo desarrolló en las últimas dos semanas, e historial de viajes en los últimos 14 días $^{32}$.

\section{Pacientes sospechosos de COVID-19}

Para pacientes que cumplen requisitos de sospecha se sugiere que no se permita su ingreso a unidad de diálisis y sean remitidos a urgencias ${ }^{31}$ para el diagnóstico de caso sospechoso y así reducir el riesgo de las demás personas de la unidad. Una postura alternativa es la separación de los pacientes sintomáticos por turno, mediante redistribución de pacientes o apertura de turnos suplementarios o ubicación en último turno del día ${ }^{8,21}$.

\section{Pacientes COVID-19 positivos}

La experiencia del Policlínico de Milán invita a que los pacientes con COVID positivo sean evaluados en urgencias para decidir si merecen hospitalización o no ${ }^{25}$; en estos casos las instituciones deben tener capacidad de administrar diálisis, tanto a nivel de cuidados moderados como en cuidados intensi$\operatorname{vos}^{8}$. Cuando los pacientes no ameritan hospitalización, se realiza diálisis y se envían de regreso a casa con recomendaciones de aislamiento estricto y obligatorio $^{25}$. Los pacientes en diálisis confirmados con COVID-19 deben continuar en la cohorte al menos siete días o hasta su recuperación ${ }^{22}$. La ISN no recomendó traslados a unidades de hemodiálisis dentro de servicios de nefrología.

De acuerdo con la experiencia de Policlínico de Milán un grupo de enfermeras realiza seguimiento de pacientes. Pacientes identificados con cuadro clínico grave, mediante la evaluación clínica de marcadores de mal pronóstico (disnea, taquipnea, taquicardia) o la aplicación de scores de gravedad 
(Quick SOFA, por ejemplo), deben ser transferidos inmediatamente a urgencias o centro hospitalario. Pacientes sin síntomas de alarma no deberían ser transferidos para evitar sobrecargar servicios ${ }^{8,29}$.

\section{Pacientes COVID-19 negativos}

Los pacientes con COVID-19 negativo son seguidos por sus síntomas y podrían ser readmitidos para dializarse con los pacientes asintomáticos ${ }^{25}$.

\section{Recomendaciones}

- Se recomienda que las unidades establezcan un protocolo de pre-triage o clasificación de pacientes.

\section{Fuerte a favor}

- Se recomienda que se implementen medidas de triage previo al ingreso del paciente a la unidad; por ejemplo, llamada el día antes de la sesión de diálisis.

\section{Fuerte a favor}

- Se recomienda que la clasificación de pacientes incluya consulta de síntomas, contacto cercano con personas sospechosas o confirmadas, y los criterios de evaluación epidemiológica según la normatividad vigente.

\section{Fuerte a favor}

- Se recomienda que los pacientes y el personal sean capacitados en la toma de temperatura 30 minutos antes de su desplazamiento hacia la unidad.

\section{Fuerte a favor}

- Se recomienda que los pacientes sean instruidos en la identificación de síntomas y el reporte a la unidad antes de presentarse.

\section{Fuerte a favor}

- Se recomienda que antes del ingreso a la unidad todos los pacientes sean valorados en busca de síntomas tanto respiratorios como no respiratorios, teniendo particular cuidado de evaluar cuadros clínicos atípicos propios de pacientes adultos mayores, multimórbidos o inmunosuprimidos, tales como: síndromes geriátricos, delirium, trastornos cognitivos, diarrea, disgeusia, anosmia, diarrea, osteomialgias, déficit neurológico, agudización de neuropatías, entre otros. Fuerte a favor

- Se recomienda incluir dentro de la evaluación de pacientes sintomáticos la aplicación de puntuaciones de gravedad como el Quick SOFA y NEWS COVID, con el fin de determinar de manera precoz el riesgo de progresión y la necesidad de traslado a urgencias.

\section{Fuerte a favor}

- Se recomienda que todo personal que ingrese a la unidad sea valorado en busca de sintomatología.

\section{Débil a favor}

- Se recomienda que pacientes y personal con temperatura superior a $38{ }^{\circ} \mathrm{C}$ o sintomatología sugestiva de COVID-19 sean evaluados por el nefrólogo, para priorizar diagnóstico de la infección, aislamiento y prevención de la transmisión en centros o unidades renales.

\section{Débil a favor}

- Se recomienda que pacientes con factores de mal pronóstico sean remitidos al servicio de urgencias.

\section{Débil a favor}

- Se recomienda tener en cuenta la clasificación de pacientes: sospechoso, COVID-19 positivo y COVID-19 negativo para la gestión de la agenda y realización de la diálisis.

\section{Fuerte a favor}

- Se recomienda realizar seguimiento de pacientes para identificar cambios en la clasificación. Fuerte a favor

- Se recomienda evitar la remisión pacientes que no presentan síntomas de alarma para evitar congestionar los servicios de urgencias y exponer al paciente a visitas con alto riesgo de contagio.

Fuerte en contra 


\section{Medidas de aislamiento}

En caso de pacientes o personal sospechoso o confirmado la información disponible sugiere que se deben extremar medidas de aislamiento. De igual manera, se sugiere para pacientes y familiares el reforzamiento del aislamiento preventivo que permita únicamente salidas necesarias relacionadas con satisfacción de necesidades básicas incluida la diálisis $^{21,25,30,33}$. Para pacientes COVID-19 se sugiere restringir el contacto con otros pacientes y personal, incluyendo su participación en áreas comunes como salas de espera y comedores ${ }^{8}$. Los movimientos de pacientes fuera de la sala de aislamiento se limitarán a propósitos esenciales, aunque deben ser evitados ${ }^{21}$. En las unidades debe evitarse aglomeraciones o reuniones en la entrada ${ }^{29}$. Por recomendación de CDC, en caso de conocer el diagnóstico, los pacientes con diferentes diagnósticos de infección respiratoria no deben ser agrupados ${ }^{21}$. En cuanto a los pacientes hospitalizados, se sugiere que se dialicen en su habitación con plantas de agua portátiles, en la medida de las posibilidades ${ }^{24}$.

El personal con sintomatología o contacto con paciente confirmado debe llevar a cabo proceso de notificación a la unidad antes de asistir y debe restringir su contacto con pacientes y otro personal ${ }^{8,21,33}$. En este sentido, es necesario llevar registro de personal sanitario y pacientes que ingresan a la unidad ${ }^{29}$. Al igual que los pacientes, el personal sospechoso o confirmado debe aislarse limitando acceso a áreas comunes y en horarios definidos; cuando las condiciones del personal lo permiten, ellos podrían continuar haciendo actividades de triage telefónico y seguimiento de pacientes, asistencia con estrategias como telesalud, asistencia a reuniones, actividades administrativas como ingreso de datos, etc. ${ }^{8}$. A la fecha no hay evidencia que respalde el uso de profilaxis posexposición para personal de la salud ${ }^{34}$.

\section{Recomendaciones}

- Se recomienda que los pacientes sospechosos y confirmados para COVID-19 tengan aislamiento estricto en el hogar y solo se desplacen hacia la unidad de diálisis para cumplir con su programación, manteniendo las precauciones de distanciamiento social y comportamiento en la comunidad.

\section{Fuerte a favor}

- Se recomienda frente a pacientes sospechosos o COVID-19 positivo extremar medidas de bioseguridad, para evitar propagación en la unidad.

\section{Fuerte a favor}

- Se recomienda restringir contacto estrecho entre pacientes confirmados COVID-19 con otros pacientes y con personal de salud.

\section{Fuerte en contra}

- Se recomienda restringir acceso a áreas comunes por parte de pacientes COVID-19 positivos. Fuerte en contra

- Se recomienda evitar el tránsito de pacientes COVID-19 positivo por las instalaciones de la unidad.

\section{Fuerte en contra}

- No se recomienda integrar pacientes con diferentes diagnósticos respiratorios.

\section{Fuerte en contra}

- Se recomienda que pacientes sospechosos sean dializados en áreas o estaciones aisladas en la medida de lo posible. La misma recomendación aplica para pacientes COVID-19 positivo.

\section{Fuerte a favor}

- En caso de que no se tenga capacidad instalada para diálisis aisladas, se recomienda generar tres turnos diferentes que correspondan a la clasificación de los pacientes o dializar a los pacientes sospechosos o COVID-19 positivos en el último turno del día y en las últimas estaciones con menor flujo de personas.

\section{Fuerte a favor}

- Se recomienda que pacientes hospitalizados con necesidad de terapia de reemplazo renal sean dializados dentro de la habitación o área aislada con plantas de agua portátiles.

\section{Fuerte a favor}


- Se recomienda llevar registro de personal sanitario en contacto con pacientes sospechosos o COVID-19 positivos.

\section{Fuerte a favor}

\section{Transporte de pacientes}

Los pacientes en terapia de reemplazo renal deben desplazarse frecuentemente entre su hogar y la unidad de diálisis, por lo que este tema toma relevancia en el cuidado de los pacientes y en general en la gestión del riesgo de los centros. En algunas unidades se ha recomendado a los pacientes evitar uso de transportes públicos y optar por vehículo propio. Para casos sospechosos o confirmados el traslado en ambulancia ha sido considerado en algunos escenarios, incluso permitiendo transporte de hasta cuatro pacientes ${ }^{8,24,29}$.

Una sugerencia común es que durante el transporte todos los integrantes del vehículo incluyendo el personal encargado del transporte deben extremar medidas de autoprotección y usar mascarillas. Además, el encargado debe estar capacitado para indagar por sintomatología ${ }^{24,31}$. Al finalizar el transporte, los vehículos deben ser desinfectados ${ }^{35}$.

\section{Recomendaciones}

- Se recomienda que pacientes que requieren asistir a las unidades de diálisis realicen sus desplazamientos en vehículo privado en la medida de las posibilidades.

\section{Fuerte a favor}

- Se recomienda evitar el uso de transporte público entre el hogar y la unidad de diálisis.

Fuerte en contra

- Se recomienda que pacientes COVID-19 positivo con requerimiento de diálisis sean transportados en vehículos destinados para pacientes COVID-19. Fuerte a favor

- Se recomienda que todos los ocupantes del vehículo usen mascarilla quirúrgica durante el desplazamiento.

\section{Fuerte a favor}

- Se recomienda que el personal encargado del transporte de pacientes indague por la presencia de síntomas.

\section{Fuerte a favor}

- Se recomienda que los vehículos que transportan pacientes de diálisis sean desinfectados al finalizar el recorrido.

\section{Fuerte a favor}

\section{Limpieza y desinfección}

Si bien las unidades renales siempre se han caracterizado por tener estrictos protocolos de limpieza y desinfección, teniendo en cuenta la naturaleza de sus procedimientos, durante la pandemia hay una llamada general a mantener la cultura de limpieza y optimizar los procesos en superficies que potencialmente mantengan el virus SARS-CoV-2. Para esto se ha sugerido que el personal encargado sea capacitado en las actividades de limpieza y desinfección específicamente, pero además en el uso de EPP y manejo de desechos (bata, guantes, mascarilla) $)^{8,21,24}$.

La limpieza de superficies externas se puede realizar con agua y jabón, seguida de solución de hipoclorito sódico. Hay recomendaciones basadas en evidencia sobre el efecto de soluciones de hipoclorito sódico con una concentración al $0,1 \%$, etanol al $62-71 \%$ o peróxido de hidrógeno al $0,5 \%$ para la desactivación del virus ${ }^{24}$.

Existe acuerdo en que la máquina de hemodiálisis utilizada en un caso sospechoso o confirmado de COVID-19 podría ser empleada a continuación para otro paciente mediante una adecuada desinfección externa con hipoclorito de sodio, tal como se realiza habitualmente y antes de retirarla de la habitación o la sala del procedimiento ${ }^{24,36}$. La sala de diálisis y los instrumentos deben ser limpiados y desinfectados dependiendo del tipo de material de que se trate, de acuerdo con los protocolos habituales del centro después de cada procedimiento ${ }^{24,25}$. Para la limpieza de sillas, máquinas y superficies la Sociedad

Revista Colombiana de Nefrología 
Internacional de Nefrología sugiere el uso de toallas desinfectantes ${ }^{29}$.

De acuerdo con las recomendaciones del gobierno de España, el transporte de material para reprocesamiento debe realizarse en contenedor cerrado. No se requieren productos especiales de limpieza y desinfección; los productos habitualmente utilizados en los centros sanitarios tienen capacidad suficiente para inactivar el virus ${ }^{24}$.

Finalmente, se sugiere que los desechos sean etiquetados y descartados de acuerdo con la clasificación de residuo que corresponda. El potencial riesgo de trasmisión por orina y heces lleva a la sugerencia de uso de bolsas absorbentes ${ }^{21,36}$.

\section{Recomendaciones}

- Se recomienda que las unidades continúen con el protocolo de limpieza y desinfección que realizan habitualmente.

\section{Fuerte a favor}

- Se recomienda que el personal encargado de la limpieza y desinfección sea reforzado e instruido en la limpieza de superficies susceptibles de depósito del virus.

\section{Fuerte a favor}

- Se recomienda que la máquina de diálisis empleada en paciente COVID-19 positivo sea desinfectada con hipoclorito de sodio de acuerdo con los protocolos de limpieza y desinfección terminal antes y después de su utilización.

\section{Fuerte a favor}

- Se recomienda el uso de soluciones de hipoclorito sódico con una concentración al $0,1 \%$, etanol al $62-71 \%$ o peróxido de hidrógeno al $0,5 \%$ para la desactivación del virus.

\section{Fuerte a favor}

- Se recomienda que el material objeto de reprocesamiento sea transportado siguiendo las recomendaciones habituales acerca de contenedores cerrados.

\section{Fuerte a favor}

- Se recomienda el adecuado proceso de eliminación de desechos, colocando etiquetas que correspondan a la clasificación del residuo.

\section{Fuerte a favor}

\section{Infraestructura y organización de uni- dades de diálisis}

Las unidades renales tienen un reto importante para enfrentar la pandemia dada la susceptibilidad de sus pacientes. Todas las medidas anteriormente expuestas requieren la integración y organización a un nivel superior. La administración de talento humano y el suministro de EPP e insumos para procedimientos son elementos claves para gestionar durante el estado de pandemia. Además, medidas logísticas y de infraestructura deben optimizarse e implementarse rápidamente para evitar contagios en el interior de las unidades. En respuesta a este gran reto, se ha identificado la necesidad de direccionar la estadía en las unidades.

La entrada de las unidades es el primer contacto con el paciente; de ahí su potencial participación como canal de comunicación de las campañas educativas, aunque se debe tener cuidado de generar aglomeraciones. El CDC y el gobierno español recomiendan que a la entrada de la unidad de diálisis y en las salas de espera se difunda información y existan dispensadores con preparados de base alcohólica para la higiene de manos, pañuelos desechables para la higiene respiratoria y contenedores de residuos con bolsa plástica y tapa de apertura con pedal para su eliminación ${ }^{21,24,37}$.

Para el ingreso de pacientes a la unidad, se han descrito diferentes posibilidades: los pacientes podrían esperar afuera la indicación de ingreso por llamada o mensaje de texto, o esperar en sala teniendo en cuenta recomendaciones de distanciamiento entre uno y dos metros en todas las direcciones ${ }^{21,24,29,31,37}$. En estos casos hay sugerencias de que las áreas de tratamiento y salas de espera tengan aire acondicionado y ventilación para eliminar partículas y aerosoles ${ }^{33}$. Además, las visitas podrían ser restringidas en las unidades. 
Respecto al personal que ingresa a sala de hemodiálisis de pacientes COVID-19, su acceso debe ser limitado para aquellos imprescindibles y en periodos breves ${ }^{29}$; esta medida podría acompañarse de un registro del personal que atiende a los casos sospechosos o confirmados ${ }^{8,21}$. Una consideración importante a tener en cuenta es la sugerencia de que pacientes COVID-19 no sean atendidos por personal en formación ${ }^{29}$. El personal de salud es un recurso valioso en la pandemia y sebe ser cuidado y administrado eficientemente.

La logística ideal de atención de pacientes en la unidad renal implicaría disponer de salas independientes y personal específico para pacientes COVID-19 y para pacientes sospechosos,

y dializarlos al tiempo; es importante establecer turnos de diálisis en los que se asegure la minimización del riesgo $0^{21,24,29,31,34,37}$. Se recomendó que en el interior de las salas de diálisis las estaciones estén separadas por lo menos un metro, durante la sesión ${ }^{29}$. El Policlínico de Milán optó por dos áreas de diálisis para pacientes COVID-19: el área A, designada para tratar pacientes con síntomas leves a moderados sin insuficiencia respiratoria, y el área $\mathrm{B}$, designada para pacientes que necesitan ventilación no invasiva (NIV) y que se configura en la unidad de cuidados intensivos COVID utilizando dos dispositivos portátiles de ósmosis inversa y dos monitores de diálisis dedicados ${ }^{25}$.

En casos en que estas medidas no puedan ser adoptadas en su totalidad, hay propuestas como dializar pacientes COVID-19 confirmados al final de la jornada y ubicarlos al final de la sala, donde exista un menor tráfico y flujo de personal ${ }^{24,30}$.

\section{Recomendaciones}

- Se recomienda la gestión del personal de salud disponible para diálisis, llevando un registro del personal y su contacto con pacientes sospechosos o COVID-19 positivos.

\section{Fuerte a favor}

- Se recomienda llevar un registro estricto de requerimientos y disponibilidad de EPP y todos los recursos necesarios para garantizar las normas de bioseguridad. Hay que establecer estrategias para predecir el requerimiento según las tendencias de uso y anticiparse al desabastecimiento.

\section{Fuerte a favor}

- Se recomienda establecer protocolos de ingreso y estancia en las unidades de diálisis.

\section{Fuerte a favor}

- Se recomienda evitar aglomeración de pacientes en las entradas de la unidad.

\section{Fuerte en contra}

- Se recomienda que los pacientes esperen afuera la indicación de ingreso a través de llamada, mensaje de texto o WhatsApp.

\section{Débil a favor}

- Se recomienda colocar dispensadores con preparados de base alcohólica para la higiene de manos, pañuelos desechables para la higiene respiratoria y contenedores de residuos con bolsa plástica y tapa de apertura con pedal para su eliminación en la sala de espera y de procedimientos.

\section{Fuerte a favor}

- Se recomienda el lavado de manos de pacientes al ingreso a la unidad.

\section{Fuerte a favor}

- Se recomienda que mientras los pacientes se encuentren en la sala de espera debe existir una distancia en todas las direcciones mínima de dos metros.

\section{Fuerte a favor}

- Se recomienda establecer rutas de movilización unidireccionales para evitar el contacto estrecho o choque.

\section{Débil a favor}

- Se recomiendan tiempos de permanencia en la unidad restringidos a los procedimientos. Esta recomendación aplica para el personal 
de salud en salas aisladas o en contacto con pacientes COVID-19.

\section{Fuerte de contra}

- Se recomienda establecer estaciones aisladas para pacientes sospechosos y COVID-19 positivos; en caso de que no sean posibles las salas aisladas, las estaciones deben estar distanciadas al menos por dos metros.

\section{Fuerte a favor}

- Se recomienda seguir técnicas de reemplazo renal establecidas y con las cuales el personal esté capacitado y familiarizado.

\section{Fuerte a favor}

- Se recomienda evitar que el personal en formación entre en contacto con pacientes COVID-19.

\section{Fuerte en contra}

- Se recomienda que las salas de espera y de procedimientos tengan dispositivos de ventilación para eliminar partículas, de acuerdo con la disponibilidad de recursos.

\section{Débil a favor}

\section{Diagnóstico clínico}

La enfermedad COVID-19 desde su aparición en diciembre del 2019 ha dejado ver diferentes manifestaciones corporales que implican diferentes sistemas. Aunque la frecuencia de los síntomas puede variar entre individuos y condiciones especiales, la mayor parte de los casos reportados coinciden en identificar síntomas semejantes. En el metaanálisis de Yanyan et al., 2020, que incluyó 1594 pacientes, se encontró que la fiebre fue el síntoma más común reportado por el $91,6 \%$ de los pacientes posteriormente diagnosticados con COVID-19, seguido de la tos en el $64,5 \%$, disnea en el $32,8 \%$, esputo en $28,1 \%$, dolor de garganta en el $11,2 \%$ y dolor de cabeza en el $10,5 \%$. La hemoptisis y la diarrea fueron menos frecuentes con porcentajes entre 3 y $7 \%{ }^{38}$. La variabilidad en la presentación de la enfermedad se muestra como un reto para especialistas de diferentes áreas para establecer casos sospechosos oportunamente.

\section{Síntomas y presentación de la enfermedad}

\section{¿Varían los síntomas y forma de presentación en población con enfermedad renal crónica en diálisis con respecto a población general?}

El comportamiento de la enfermedad en pacientes con enfermedad renal crónica (ERC) hasta ahora no está claramente establecido a pesar de avances en el tema. La mayoría de información disponible orientada a enfermedad renal se basa en reporte de casos clínicos y series de casos.

El reporte de caso de Tang et al. presenta un hombre de 50 años en hemodiálisis, con antecedente de hipertensión y diabetes, que inicia con tos no productiva; al ingreso hospitalario estaba hipertenso (184/ $107 \mathrm{~mm} \mathrm{Hg}$ ) y con taquicardia. Las pruebas de laboratorio mostraron un recuento de glóbulos blancos de $3,38 \times 109 / 1$ con $77,5 \%$ de neutrófilos, $15,7 \%$ de linfocitos y $0 \%$ de eosinófilos. Los niveles de proteína $\mathrm{C}$ reactiva y procalcitonina fueron $40,1 \mathrm{mg} / \mathrm{l}$ y 0,73 $\mathrm{ng} / \mathrm{ml}$, respectivamente. La función hepática y los niveles de enzimas cardíacas estaban dentro del rango normal. La tomografía computarizada de tórax mostró opacidades bilaterales de vidrio esmerilado.

Una presentación atípica de la enfermedad fue reportada por Ferrey et al. Se trata del caso de un paciente de 56 años con requerimiento de terapia de reemplazo renal con hemodiálisis que desarrolló síntomas gastrointestinales que incluyeron náuseas, emesis, diarrea y dolor abdominal; además, presentó fiebre. Los síntomas respiratorios se presentaron cinco días después del inicio de la sintomatología, con una rápida progresión a síndrome de dificultad respiratoria aguda (SDRA) que requirió soporte ventilatorio $^{39}$. Otro caso atípico se reportó para un paciente de 75 años con enfermedad renal en estadio final, afebril $\left(36,8{ }^{\circ} \mathrm{C}\right)$, con taquipnea (23 respiraciones/minuto) y taquicardia (100 latidos por minuto) y cifras tendientes a hipertensión (138/89 $\mathrm{mm} \mathrm{Hg}$ ); no tuvo acceso a diálisis durante cinco días por medidas de aislamiento en la ciudad. El paciente presentó edema en miembros inferiores ${ }^{40}$. Las pruebas de laboratorio mostraron $\mathrm{Cr} 1423,3 \mu \mathrm{mol} / 1$, BUN $40 \mu \mathrm{mol} / \mathrm{l}$, potasio $4,63 \mathrm{mmol} / \mathrm{L}$ y ácido úrico $760 \mu \mathrm{mol} / \mathrm{L}$. Este caso es otra presentación atípica

132 Consenso colombiano de expertos sobre recomendaciones informadas en la evidencia para... 
de la enfermedad; el paciente no desarrolló síntomas respiratorios.

Una serie de casos reportada por un centro de hemodiálisis en el Hospital de la Universidad de Wuhan indicó que en pacientes en diálisis se desarrollaba linfopenia con menor frecuencia, los niveles séricos de citosinas inflamatorias eran más bajos y la enfermedad tuvo una presentación más leve, al menos en las primeras etapas de la enfermedad, respecto a lo esperado para población general ${ }^{33}$, probablemente debido a la función reducida del sistema inmune y la disminución de las tormentas de citoquinas ${ }^{11,41}$. Un análisis de muestras de sangre periférica de pacientes del mismo centro de hemodiálisis reportó disminución en el número de células $\mathrm{T}$ y células asesinas (NK) en células mononucleares de sangre periférica humana en comparación con pacientes que no recibieron hemodiálisis ${ }^{11}$. Rombóla et al. sugieren la presentación leve de la enfermedad con síntomas semejantes al resfriado común ${ }^{41}$.

La serie de cinco casos reportada por Wang et al. describió pacientes entre 47 y 67 años, en quienes la diarrea, la fiebre y la fatiga fueron los síntomas más comunes. También presentaron disnea, dolor abdominal y tos. Además, todos los pacientes presentaron linfopenia y opacidad en vidrio esmerilado según tomografía de tórax ${ }^{42}$.

\section{Recomendaciones}

- Se recomienda tener en cuenta que los pacientes con enfermedad renal pueden cursar presentaciones atípicas de la enfermedad COVID-19 debido a condición inmune que disminuye la tormenta de citoquinas.

\section{Fuerte a favor}

- Se recomienda incluir en la definición de paciente sintomático de COVID-19 para paciente con enfermedad renal síntomas gastrointestinales: diarrea, emesis, náuseas, dolor abdominal.

\section{Fuerte a favor}

- Se recomienda incluir la sintomatología gastrointestinal en los procesos de tamización y clasificación de pacientes.

Fuerte a favor

\section{Prueba diagnóstica}

¿Varía el rendimiento de las diferentes pruebas de diagnóstico para COVID-19, moleculares y serológicas, en los pacientes renales crónicos?

A la fecha no existe información específica de pruebas diagnósticas orientadas a pacientes con enfermedad renal. Los casos diagnosticados en pacientes con enfermedad renal, reportados a la fecha, se realizaron a través de la prueba RT-PCR específica para SARS-CoV-2 /COVID ${ }^{7,11,33,39-42}$. El Ministerio de Salud y Protección Social sugiere el uso de pruebas serológicas para identificar el contacto previo de una persona con el virus SARS- CoV-2. Se podrán realizar pruebas rápidas de anticuerpos $\mathrm{IgM} / \mathrm{IgG}$ en personas con síntomas leves mayores a 10 días y sin factores de riesgo; contactos estrechos con síntomas leves por más de 10 días y sin factores de riesgo; personas asintomáticas con o sin factores de riesgo en el marco de estudios epidemiológicos o de salud pública $^{2}$. ACIN sugiere continuar el diagnóstico a través de la prueba RT-PCR, para la cual se ha demostrado el rendimiento operativo en función del lugar de toma de muestra, el cual es mayor en el lavado broncoalveolar con sensibilidad del 93\%, el aspirado bronquial o esputo con el $72 \%$ y el hisopado naso y orofaringeo con el $63 \%$. ACIN no recomienda la toma a través de esputo por la formación de aerosoles².

\section{Recomendación}

- Se recomienda realizar el diagnóstico de SARS-CoV-2 en pacientes con enfermedad renal con la prueba diagnóstica de uso actual en el país: la RT-PCR.

\section{Fuerte a favor}

- Se recomienda considerar el uso de pruebas serológicas en pacientes con enfermedad renal asintomáticos con historia de contacto con casos sospechosos o confirmados.

\section{Fuerte a favor}

\section{Pronóstico}

Los desenlaces de la enfermedad COVID-19 reportados incluyen muerte, complicaciones como 
sepsis, lesión renal aguda, SDRA, lesión cardiaca aguda, bacteremia, shock, alcalosis, hipercalemia y encefalopatía isquémica ${ }^{4,43,44}$. Datos de mortalidad reportados en población varían entre 2 y $15 \%{ }^{11,38,45}$. La comorbilidad se ha relacionado con presentaciones graves de la enfermedad y muerte ${ }^{43}$.

En el estudio de Zhou et al. para adultos hospitalizados con COVID-19 en Wuhan, el 48\% tenían comorbilidad, siendo la más común la hipertensión reportada para el 30\% de los pacientes, seguida de diabetes con $19 \%$ y enfermedad coronaria con $8 \%$. Henry y Lippi, en un metaanálisis preliminar encontraron que pacientes con ERC tienen mayor posibilidad de desarrollar COVID-19 grave (OR de 3,03, IC95\% 1,09 a 8,47$)^{17}$.

La edad avanzada, la puntuación SOFA más alta y el dímero $\mathrm{D}$ superior a $1 \mu \mathrm{g} / \mathrm{ml}$ al ingreso fueron variables asociadas con la mayor probabilidad de muerte en población general hospitalizada. Además, hubo asociación de este desenlace con linfopenia, leucocitosis ( $>10 \times 109 / 1)$, alanino aminotransferasa (ALT) elevada (>40 U/1), lactacto deshidrogenanasa ( $>245 \mathrm{U} / \mathrm{l})$, troponina cardiaca de alta sensibilidad $(>28$ $\mathrm{pg} / \mathrm{ml})$, creatina quinasa (>185 U/l), ferritina sérica (>300 $\mu \mathrm{g}$ ), interleuquina-6 (IL-6), tiempo de protrombina, creatinina, procalcitonina y trombocitopenia $^{4,44,46}$. De la misma manera, Zhan et al. sugirieron que la edad, el sexo masculino, los puntajes APACHE II y SOFA más altos, la procalcitonina elevada, el excesivo volumen de líquido y el uso retrasado de costicoesteroides aumentaron el riesgo de presentación grave de la enfermedad y muerte en la población general ${ }^{43}$.

\section{Factores pronóstico}

¿Qué factores de riesgo asociados a la enfermedad renal crónica en estadio 5 son determinantes pronósticos en COVID-19?

Es limitada la evidencia de factores de riesgo y desenlaces de pacientes con ERC y COVID-1947. La información disponible sugiere que la enfermedad renal, especialmente de pacientes en ERC estadio final con indicación de hemodiálisis, podría tener un mayor riesgo de COVID-19 grave y complica- ciones, debido condiciones basales de los pacientes, incluida la edad, las comorbilidades y el inmunocompromiso ${ }^{7,15,18,39,45}$. La enfermedad renal estuvo presente entre el 1 y 4,3\% de los pacientes reportados que desarrollaron COVID-19, la mayoría de ellos con presentaciones graves de ella y, al menos en el estudio de Zhou, ninguno sobrevivióo ${ }^{4,16,43}$. La tasa de infección en pacientes con ERC en estadio final fue de $16 \%^{16}$.

En el estudio de Manganaro, se estimó una tasa de mortalidad de $24,6 \%$ en pacientes en TRR, la cual fue mayor en hombres que en mujeres. El riesgo comparativo de mortalidad respecto a la población general en la región fue 2,8 veces mayor en pacientes en TRR (OR: 3,8 IC95\% 2,53 a 5,72). La enfermedad cardiovascular fue asociada a la muerte en cerca del $30 \%$ de los casos. La diabetes fue un factor de riesgo en pacientes trasplantados ${ }^{15}$. La posible asociación de ERC con presentaciones graves de la enfermedad y muerte ha sido explicada hasta ahora por su relación con la enzima convertidora de angiotensina 2 (ECA-2) ${ }^{29}$.

\section{Recomendaciones}

- Se recomienda incluir, como factor de riesgo para mal pronóstico de COVID-19 en paciente con enfermedad renal, la terapia de reemplazo renal.

\section{Fuerte a favor}

- Se recomienda tener en cuenta los mismos factores de riesgo para mal pronóstico de COVID-19 considerados para la población general: edad mayor a 60 años y comorbilidades, al menos hasta que haya nueva evidencia para pacientes con ERC estadio final. Fuerte a favor

\section{Dímero-D y ferritina}

\section{¿Es equiparable el dímero $D$ con la ferritina en este grupo poblacional?}

La ferritina sérica es un biomarcador inmunológico incrementado en pacientes que cursan con COVID-19, siendo diferencial en población sobre-

134 Consenso colombiano de expertos sobre recomendaciones informadas en la evidencia para... 
viviente de COVID-19 (DMP 408,3 ng/ml IC95\% 311,1 a 505,4 ) y no sobreviviente (DMP 760,2 ng/ml IC95\% 560,8 a 959,5). Los autores sugieren la IL-6 y la ferritina sérica como biomarcadores de pronóstico en pacientes hospitalizados ${ }^{46,48}$. El dímero-D es descrito en varias publicaciones por su importancia en el pronóstico de la enfermedad; Zhou et al. encontraron que valores superiores a $1 \mu \mathrm{g} / \mathrm{ml}$ aumentan la probabilidad de muerte $4,49,50$. El $75 \%$ de los pacientes con COVID-19 tuvo incrementos de dímero- $\mathrm{D}^{51}$. Debe tenerse en cuenta que pacientes en hemodiálisis por edad la edad y otras condiciones como anemia, enfermedad aguda reciente, acceso vascular, anticoagulación, hemodiálisis y enfermedades crónicas pueden tener niveles de dímero-D y ferritina diferenciales a los de la población general. En el estudio de Karaboyas et al. en 2015, se reportó promedio de ferritina superior a $800 \mathrm{ng} /$ ml en población en hemodiálisis, y en el estudio de Gubensek et al. en 2016 la mediana de dímero-D fue $966 \mu \mathrm{g} / 1$ y al menos el $75 \%$ de esta población tenía valores superiores a $500 \mu \mathrm{g} / \mathrm{l}^{52,53}$. La ACIN sugiere incluir la ferritina mayor a 1000 y el dímero-D mayor a $1 \mathrm{mcg} / \mathrm{ml}$ dentro de los marcadores de mal pronóstico de COVID-192.

Respecto a biomarcadores pronósticos en pacientes con ERC estadio final, la información es escasa. De los reportes de casos y series de caso disponibles en pacientes con ERC solo el reporte de Dian Fu et al. describe el comportamiento de dímero-D en un paciente diagnosticado con COVID-19 y ERC estadio final. El paciente ingresó con valor de dímero-D de 3,51 mg/l (reportado el día 2 de hospitalización), los días siguientes incrementó en 1,24 unidades, alcanzando el mayor valor reportado $(4,75 \mathrm{mg} / \mathrm{l})$, y los días siguientes la tendencia fue a la disminución hasta alcanzar 2,45 mg/l. El paciente tuvo desenlace favorable.

\section{Recomendaciones}

- Se recomienda usar los marcadores para mal pronóstico de COVID-19 propuesto para la población general según la ACIN, al menos hasta que haya nueva evidencia en pacientes con ERC en estadio final.

\section{Fuerte a favor}

- Se recomienda realizar seguimiento a cambios en los valores de ferritina y de dímero-D, analizando cada caso de manera independiente, teniendo en cuenta que pacientes en hemodiálisis por defecto podrían tener este marcador incrementado y su resultado podría variar dependiendo de si la medición se hace antes o después de la diálisis.

\section{Fuerte a favor}

\section{Terapia de diálisis}

En Colombia en el año 2018 se reportaron más de 40.000 personas en estadio 5. El 59\% de los casos en TRR se encontraban en hemodiálisis, el 22 $\%$ en diálisis peritoneal y el $18 \%$ recibieron trasplante ${ }^{5}$.

\section{Hemodiálisis}

Los pacientes en TRR son una población susceptible de contagio por condiciones de base y adicionalmente por no adoptar las medidas de distanciamiento social de manera estricta debido a la necesidad de asistir a unidad de diálisis tres veces a la semana para recibir su tratamiento ${ }^{8,11,30}$.

\section{¿Qué estrategias en los pacientes de hemodiálisis durante el periodo de infección o síntomas en los pacientes confirmados con COVID-19 se pueden tener en cuenta?}

En vista de la necesidad de gestionar el riesgo de contagio para pacientes con ERC en hemodiálisis y personal de la salud, la información disponible sugiere que es necesario implementar medidas de prevención dentro de la unidad, específicamente orientadas a contener el riesgo desde la fuente, es decir, desde el paciente sospechoso o COVID-19 positivo.

Las estrategias disponibles son reportadas en función de la condición clínica del paciente y la disponibilidad de recursos; estas incluyen la transferencia de pacientes a programa de diálisis domiciliaria o a servicios de emergencia para que los sospechosos sean tamizados o sus diálisis sean 
realizadas en unidades rutinarias extremando la bioseguridad e implementando medidas de aislamiento y seguimiento remoto para prevenir complicaciones y mejorar la capacidad de atención ${ }^{18,22,23,54}$. Reducción en la velocidad de flujo de dializado a máximo $600 \mathrm{ml} / \mathrm{min}$, disminución de frecuencia de dializado de tres a dos veces por semana, restricción de líquidos, bloqueo de nefronas y hemodiálisis intermitente son algunas estrategias que permitirían ahorrar tiempos e insumos ${ }^{10,22}$.

En pacientes sospechosos de COVID-19 que presenten cambios en estado de cohorte se ha de administrar la diálisis de acuerdo con el estado de cohorte relevante, intentando retrasar la diálisis analizando la condición del paciente y registrando e informando cada decisión a pacientes y familiares ${ }^{22}$.

Recomendaciones disponibles sugieren continuar con modalidades existentes y evitar cambios de procedimientos; además, se refuerza en la necesidad de filtrar moléculas de tamaño medio para eliminar mediadores inflamatorios ${ }^{12,14,55}$. En el caso de signos de lesión renal aguda (LRA), la información disponible sugiere utilizar posibles intervenciones, incluida la TRR continua ${ }^{56}$.

En pacientes críticos hospitalizados con requerimiento de soporte vital, se sugiere diálisis peritoneal automatizada o TRR continuas que permiten eliminar toxinas potencialmente dañinas y estabilizar el estado metabólico y hemodinámico ${ }^{40}$; determinando el volumen de filtración y la mejor modalidad a través del cálculo de peso $\operatorname{seco}^{32}$. Pacientes que cumplan indicaciones para inicio de TRR o requieran acceso vascular deberían ser sometidos al procedimiento por especialistas con experiencia ${ }^{36}$; debido a que las cirugías se han escatimado para urgencias, la colocación de catéter debe ser priorizada en la pandemia ${ }^{57}$. No se ha recomendado la nebulización durante la diálisis, por el riesgo de aerosoles ${ }^{37}$.

\section{Recomendaciones}

- Se recomienda implementar medidas preventivas declaradas en la sección de prevención del presente documento.

Fuerte a favor
- Se recomienda implementar estrategias de seguimiento remoto para evitar complicaciones. Fuerte a favor

- Se recomienda implementar estrategias que favorezcan la capacidad de atención en unidades de diálisis.

Fuerte a favor

- Se recomienda que pacientes COVID-19 reciban diálisis de acuerdo con estado de cohorte. Fuerte a favor

- Se recomienda llevar registro de decisiones de reprogramación de diálisis con argumentos de la decisión.

\section{Fuerte a favor}

- Se recomienda informar a pacientes y familiares acerca de decisiones del procedimiento.

Fuerte a favor

- Se recomienda continuar con modalidades instauradas a menos que la condición del paciente amerite cambios.

Fuerte a favor

- Se recomienda evitar incursionar en nuevas modalidades con las que el personal no está familiarizado ni capacitado.

Fuerte en contra

- Se recomienda filtrar moléculas de tamaño medio que favorezcan la eliminación de mediadores inflamatorios.

Fuerte a favor

- Se recomienda priorizar la colocación de catéter y el acceso vascular en agendas de cirugía. Fuerte a favor

\section{Diálisis peritoneal}

\section{¿Qué recomendación se debe realizar con pa- cientes en diálisis peritoneal?}

Los pacientes en diálisis peritoneal tienen una potencial ventaja sobre los pacientes en hemodiálisis 
ambulatoria respecto al seguimiento de medidas de confinamiento, por lo que las recomendaciones para el manejo de estos pacientes se orientan a mantener las condiciones clínicas y de suministros para 15 o 30 días, de manera que les permitan continuar en esta modalidad de tratamiento. Por lo tanto, las medidas reportadas incluyen la educación acerca de COVID19 y la identificación de signos y síntomas, además del seguimiento por parte de personal de salud a nivel domiciliario y la implementación de estrategias de teleasistencia según cada caso $^{8,29,41,57}$. Se sugiere evitar procedimientos no esenciales como PET y medidas de aclaramiento ${ }^{32}$.

No hay información acerca de eliminación del virus SARS-CoV-2 por líquido peritoneal ${ }^{29}$; sin embargo, el manejo propuesto es variable. Según la Sociedad Internacional de Diálisis Peritoneal (ISPD, por siglas en inglés) hay sugerencias de continuar la práctica rutinaria, mientras otros proponen utilizar solución clorada en proporción de 500 $\mathrm{mg} / \mathrm{l}$ durante una hora antes de su descarte en el inodoro y evitar salpicaduras de gotas al descargar el inodoro ${ }^{32}$.

\section{Recomendaciones}

- Se recomienda continuar con la práctica habitual de que los pacientes tengan insumos de diálisis para 15 a 30 días.

\section{Fuerte a favor}

- Se recomienda reforzar información de COVID19 y la identificación de signos de alarma.

\section{Fuerte a favor}

- Se recomienda realizar seguimiento domiciliario a pacientes con diálisis peritoneal.

\section{Fuerte a favor}

- Se recomienda implementar estrategias de teleasistencia para acompañamiento durante los procedimientos.

Débil a favor

- Se recomienda mantener contacto continuo con los pacientes para evitar complicaciones. Fuerte a favor
- Se recomienda continuar el manejo habitual de líquidos de diálisis peritoneal.

\section{Fuerte a favor}

- Se recomienda utilizar solución clorada en proporción de $500 \mathrm{mg} / \mathrm{l}$ durante una hora antes de su descarte de líquidos en el inodoro.

\section{Débil a favor}

- Se recomienda evitar salpicaduras de gotas al descargar el inodoro.

\section{Fuerte en contra}

\section{Requerimiento de cuidado crítico}

Alrededor del 5\% de los pacientes COVID-19 requieren manejo en unidad de cuidado intensivo para vigilancia estricta y soporte vital (UCI). En la serie de casos reportada por Huang, los pacientes con mayor riesgo de mortalidad por la edad, las comorbilidades y la inmunosupresión requieren manejo en $\mathrm{UCI}^{58}$, condiciones que son frecuentes en pacientes con ERC. NICE y la Asociación Colombiana de Medicina Crítica y Cuidado Intensivo (AMCI) sugieren acogerse a criterios habituales analizando la gravedad de la enfermedad, las comorbilidades (severidad y clase funcional), el potencial de recuperación, los aspectos éticos, la preferencia de paciente o familia y los resultados de escalas objetivas de severidad ${ }^{22,58}$.

\section{¿Cambian los criterios de ingreso a UCI en el paciente en diálisis?}

No se encontró información específicamente para indicaciones de ingreso a UCI en pacientes con ERC. Hasta ahora los criterios de ingreso a UCI de paciente COVID-19 adoptados en Colombia se basan en la clasificación de caso 1 según el Ministerio de Salud, signos vitales, examen físico identificando signos de dificultad respiratoria y puntaje en escala NEWS entre 5 y 7 o q-SOFA $>2^{58}$.

\section{Recomendaciones}

- Se recomienda adherirse a las indicaciones de ingreso a UCI sugeridas por la AMCI para paciente sospechoso o COVID-19, al menos 
hasta que exista información específica para paciente con ERC.

\section{Fuerte a favor}

\section{Herramientas de evaluación del riesgo y pronóstico}

Las herramientas empleadas para definir la gravedad y el pronóstico de pacientes COVID-19 de manera objetiva incluyen la escala NEWS que considera como parámetros la edad, la frecuencia respiratoria, la saturación de oxígeno, la suplencia de oxígeno, la tensión arterial sistólica, la frecuencia cardiaca y la temperatura. La clasificación del riesgo se presenta en cuatro categorías: bajo, medio, alto y muy alto ${ }^{59}$. En la cohorte retrospectiva publicada por Zhou, se encontró que puntuaciones altas en la escala qSOFA se asociaron con mayor riesgo de muerte en pacientes COVID-194.

\section{¿Las herramientas de evaluación del riesgo y el pronóstico cambian en la población?}

No se encontró información específica de herramientas de evaluación de riesgo y pronóstico para pacientes con ERC. En Colombia la ACMI propone las escalas NEWS y qSOFA para la predicción de riesgo y gravedad de pacientes COVID-19 y la indicación de ingreso a $\mathrm{UCI}^{60}$.

\section{Recomendaciones}

- Se recomienda el uso de herramientas de evaluación de riesgo y pronóstico en pacientes con COVID-19 y ERC, para orientar la práctica clínica y optimizar la prestación de servicios.

Fuerte a favor

- Se sugiere utilizar las escalas NEWS, qSOFA y PNEWS en población infantil con ERC. Fuerte a favor

\section{Consideraciones éticas}

En época de pandemia la prestación de servicios en salud tiene un reto importante al enfrentar el aumento de la demanda que supone la infección por
SARS-CoV-2, sobre todo para las UCI dada la necesidad de soporte vital y ventilación mecánica que requieren estos pacientes. A pesar de esto, todos los pacientes deberían recibir atención compasiva ${ }^{61}$.

En el peor escenario que curse con escasez de recursos y de capacidad instalada, se esperaría que existan criterios definidos de priorización que sean objetivos y transparentes. Los criterios deberían basarse en principios de proporcionalidad, justicia distributiva y equidad ${ }^{62}$. En este sentido, la experiencia del Hospital Brigham sugiere que exista un comité de supervisión del proceso de priorización y la oportunidad de discutir con los pacientes ${ }^{61}$.

Al respecto existe acuerdo en que las medidas clínicas deben ser analizadas de cara al riesgo y potenciales resultados basados en las condiciones basales del paciente (edad, comorbilidades, funcionalidad) y el pronóstico ${ }^{63,64}$. Independientemente de la decisión, todas deberían ser analizadas rápidamente, caso por caso, y registradas e informadas a pacientes y familiares.

\section{Oportunidad UCI}

¿Qué consideraciones éticas en el momento de decidir oportunidad de UCI se deben tener en cuenta en los pacientes con enfermedad renal crónica?

La información disponible al respecto se orienta a aspectos éticos en las decisiones clínicas orientadas a pacientes COVID-19 en escenarios que requieran priorizar la oportunidad de la atención en la UCI, sin ser específica para pacientes con ERC. La principal premisa para priorizar es salvar la mayor cantidad de personas, por lo que la medición de gravedad y pronóstico y el análisis de riesgo-beneficio son parámetros que deberían ser considerados objetivamente ${ }^{58,64}$.

\section{Recomendaciones}

- Se recomienda que cada institución con UCI tenga un protocolo de priorización de admisión de pacientes con una visión holística y multidisciplinar que permita el concurso y la 
evaluación conjunta con las áreas de geriátrica y de cuidado paliativo.

\section{Fuerte a favor}

- Se recomienda basar los criterios de priorización en principios éticos de justicia distributiva, equidad, proporcionalidad, confianza, deber de atención, transparencia, consistencia y responsabilidad.

\section{Fuerte a favor}

- Se recomienda considerar en los parámetros de admisión a UCI las condiciones basales del paciente, la relación del riesgo versus el resultado clínico potencial y el pronóstico del paciente medido objetivamente.

\section{Fuerte a favor}

- Se recomienda tener un comité de supervisión y un registro de la priorización de pacientes y los argumentos para la decisión.

\section{Fuerte a favor}

- Se recomienda informar a pacientes y familiares acerca del protocolo y proceso de priorización.

\section{Fuerte a favor}

- Se recomienda garantizar el cuidado compasivo de todos los pacientes, incluyendo su adecuado control de síntomas y la importancia de acompañar sus necesidades psicológicas y emocionales.

\section{Fuerte a favor}

\section{Voluntades anticipadas}

¿Está recomendada en los pacientes con enfermedad renal crónica en diálisis la implementación de voluntades anticipadas?

La voluntad anticipada es una herramienta que captura las preferencias de pacientes cuando por alguna condición no pueda tomar la decisión de manera consciente. En Colombia, esta acción está reglamentada en la resolución 2665 de 2018. En las circunstancias de COVID-19, los pacientes con mal pronóstico podrían manifestar su preferencia sobre el final de la vida y su posición frente a las modalidades terapéuticas que requerirían en caso de estar gravemente enfermos. Estas medidas aplican para todas las personas y aún más para aquellas con pronósticos fatales. No se encontró información específica para ser considerada en pacientes con COVID-19 y ERC. La AMCI sugiere que los pacientes sean consultados acerca de voluntades anticipadas ${ }^{65}$. El Ministerio de Salud y Protección Social de Colombia y las Sociedades Españolas de Medicina Intensiva y Cuidado Paliativo sugieren considerar los siguientes aspectos durante la emergencia por COVID-1966-68:

- El proceso de información del cuidado de la enfermedad debe incluir la información sobre el ejercicio de derechos al final de la vida incluyendo la adecuación de los esfuerzos terapéuticos y la suscripción de documentos de voluntad anticipada.

- Ante la circunstancia concreta de rechazo terapéutico de cuidados específicos, se debe buscar garantizar los procesos de cuidado y alivio sintomático, y la ubicación del personal de salud que pueda vigilar y acompañar los desenlaces previsibles.

- Hay que recordar que el hecho de no llevarse a UCI por voluntades anticipadas o por distribución de recursos, si fuese el caso, no implica abandono en su cuidado.

- Es importante lograr una adecuada comunicación entre el paciente, la familia y su equipo de salud para respetar las voluntades anticipadas, pero brindar una información completa, eficiente y continúa sobre el estado de salud y las alternativas de tratamiento.

- Las decisiones de adecuación terapéutica, idealmente, se deben consensuar con el paciente y/o familiares, pero en esta situación excepcional puede ser difícil tomar decisiones. En estos casos, si no hay posibilidad de consensuar las decisiones, hay que recordar que el garante de la toma de decisiones es el equipo sanitario del paciente y el registro en la historia clínica. 


\section{Recomendaciones}

- Se sugiere que pacientes con ERC que cursen con enfermedad COVID-19 con indicadores de mal pronóstico sean consultados acerca de preferencias al final de la vida si su pronóstico no cambiará.

Fuerte a favor

- Se sugiere que los nefrólogos estén capacitados para consultar a los pacientes acerca de voluntades anticipadas.

Fuerte a favor

- Se sugiere que las voluntades anticipadas de pacientes con ERC y COVID-19 queden documentadas, preferiblemente con testigo o soporte en video.

Fuerte a favor

\section{Salud mental}

Aunque el personal de salud y los pacientes en condiciones especiales se enfrentan a situaciones estresantes en la cotidianidad, el estado actual de la pandemia los ha puesto ante situaciones más complejas que incluyen el miedo relacionado con la exposición y la posibilidad de contagio y el pronóstico de la enfermedad ante COVID-19. Mientras que los personales de la salud, siendo el único frente directo con la epidemia, se enfrentan a diario a situaciones de frustración por desenlaces fatales, algunos con mayor carga de trabajo, ansiedad por hechos contextuales de discriminación, en fin, un sin número de condiciones que afecta emocional y mentalmente a estas dos poblaciones ${ }^{69,70}$.

Al respecto, NICE llama a apoyar al personal y los pacientes con ERC para mantenerse en contacto tanto como sea posible a través de diferentes herramientas de teleasistencia, telefonía y tecnológicas, mantenerlos informados y hacerlos partícipes de programas nacionales como Kidney Care $\mathrm{UK}^{22}$. Otras alternativas sugieren la promoción de actividad física, asistencia psicológica y actividades cognitivas ${ }^{70}$. Específicamente para personal de la salud se propone la gestión adecuada de recursos tanto de personal como de EPP e insumos para el desarrollo óptimo de sus actividades, de información ${ }^{69}$.
¿Qué recomendaciones se deben tener en cuenta en cuanto a salud mental y apoyo psicológico de pacientes en diálisis?

Pacientes con ERC considerados como una condición especial, con alto riesgo de contagio debido a su continua exposición a escenarios clínicos para TRR, en su mayoría con condiciones basales asociadas al pronóstico del COVID-194, se están enfrentando a temores relacionados con el riesgo de la enfermedad COVID-19 y a su pronóstico. La información relacionada con la salud mental de estos pacientes ha sido analizada tangencialmente por NICE, recomendando acompañamiento continuo y apoyo psicológico ${ }^{22}$.

\section{Recomendaciones}

- Se recomienda que las unidades renales implementen estrategias de cuidado de salud mental para pacientes y personal de salud.

Fuerte a favor

- Se recomienda mantener contacto con los pacientes a través de llamadas telefónicas, teleasistencia u otras herramientas tecnológicas. Fuerte a favor

- Se recomienda brindar apoyo psicológico a pacientes y personal de la salud, al menos durante la epidemia.

Fuerte a favor

- Se recomienda promover el autocuidado y el desarrollo de actividades en casa.

Fuerte a favor

\section{Conflicto de interés}

Todos los autores declararon su conflicto de interés a través de un formato predefinido, el cual se encuentra en custodia del comité metodológico. Adalberto Peña Wilches recibió recursos de Nikkiso de Colombia en 2020; Alfonso Bunch es accionista de Baxter; David Ballesteros recibió recursos de AMGEN en 2014; Freddy Ardila es accionista y empleado de RTS filial de Baxter; Juan Guillermo Vargas ha recibido recursos de Alexion Colombia, Medtronic 
Colombia y Biomeriux Colombia; Luis Alfonso Valderrama Cometa ha recibido recursos de Alexium y fue socio del Centro Médico Imbanaco, Cali; María José Vargas Brochero ha recibido recursos de RTS, y Mercedes Alfaro Tejeda ha recibido recursos de Shire (2016), Novordisk (2019) y Meak Sharp \& Dohme (2019). Los demás autores declararon no tener conflicto de interés.

\section{Responsabilidades éticas}

\section{Protección de personas y animales}

Los autores declaran que para esta investigación no se han realizado experimentos en seres humanos ni animales.

\section{Confidencialidad de los datos}

Los autores declaran que han seguido los protocolos de su centro de trabajo sobre la publicación de datos de pacientes.

\section{Derecho a la privacidad y consentimiento informado}

Los autores declaran que en este artículo no aparecen datos de pacientes.

\section{Contribución de los autores}

Nancy Yomayusa, Gustavo Aroca, Richard Baquero, Erika Yama, Camilo González, Adriana Robayo, Amaury Ariza, Juan Guillermo Vargas, Jorge Rico, Roberto Ramírez, Rodolfo Torres y Kelly Chacón participaron en el diseño y ejecución del consenso. Los demás autores participaron como expertos clínicos en la consulta de recomendaciones. Todos los autores participaron en la construcción del manuscrito y aprobaron su contenido. 


\section{Referencias}

1. Dong E, Du H, Gardner L. An interactive web-based dashboard to track COVID-19 in real time. Lancet Infect Dis [Internet]. 2020;20(5):533-4. http://dx.doi.org/10.1016/S1473-3099(20)30120-1

2. Zhou F, Yu T, Du R, Fan G, Liu Y, Liu Z, et al. Clinical course and risk factors for mortality of adult inpatients with COVID-19 in Wuhan, China: a retrospective cohort study. Lancet [Internet]. 2020;395(10229):1054-62. https://doi.org/10.1016/S0140-6736(20)30566-3

3. Cuenta de Alto Costo (CAC). Boletín de información técnica especializada de la cuenta de alto costo. 2018. https://cuentadealtocosto.org/site/investigaciones/

4. Cuenta de Alto Costo (CAC). Situación de la enfermedad Renal Crónica, Hipertensión arterial y Diabetes Mellitus en Colombia 2018. 2018. https://cuentadealtocosto.org/site/publicaciones/situacion-de-la-enfermedad-renal-cronica-la-hipertension-arterial-y-la-diabetesmellitus-en-colombia-2018/

5. Angel-Korman A, Brosh T, Glick K, Leiba A. [COVID-19, THE KIDNEY AND HYPERTENSION]. Harefuah. 2020;159(4):231-4.

6. Tang B, Li S, Xiong Y, Tian M, Yu J, Xu L, et al. Coronavirus Disease 2019 (COVID-19) Pneumonia in a Hemodialysis Patient. Kidney Med [Internet]. 2020;2(3):354-8. https://doi.org/10.1016/j.xkme.2020.03.001

7. Instituto de Evaluación Tecnológica en Salud, Asociación Colombiana de Infectología. Consenso colombiano de atención, diagnóstico y manejo de la infección por SARS-COV-2/COVID-19. Rev Colomb infectología. 2020;24:47.

8. Sociedad Latinoamericana de Nefrología e Hipertensión. Recomendaciones para el manejo de pacientes portadores de enfermedad renal frente a la epidemia de coronavirus (COVID-19). 2020;(15).

9. Joanna Briggs Institute. The Joanna Briggs Institute Scientific Writer Handbook. 2018;29. http://joannabriggs-webdev.org/assets/docs/ scientificWriters/JBI Scientific Writer Handbook_July 2018.pdf

10. Burgner A, Ikizler TA, Dwyer JP. COVID-19 and the Inpatient Dialysis Unit: Managing Resources During Contingency Planning PreCrisis. Clin J Am Soc Nephrol. 2020;15(5). https://doi.org/10.2215/CJN.03750320

11. Perico L, Benigni A, Remuzzi G. Should covid-19 concern nephrologists? why and to what extent? The emerging impasse of angiotensin blockade. Nephron [Internet]. 2020;144:213-21. https://doi.org/10.1159/000507305

12. Alberici F, Del Barba E, Manenti C, Econimo L, Valerio F, Pola A, et al. [Managing patients in dialysis and with kidney transplant infected with Covid-19]. G Ital Nefrol. 2020 Apr;37(2).

13. Haberal M. COVID-19 UPDATE. Vol. 18, Experimental and clinical transplantation?: official journal of the Middle East Society for Organ Transplantation. Turkey; 2020. p. 139-40.

14. Scarpioni R, Manini A, Valsania T, De Amicis S, Albertazzi V, Melfa L, et al. Covid-19 and its impact on nephropathic patients: the experience at Ospedale "Guglielmo da Saliceto" in Piacenza. G Ital Nefrol [Internet]. 2020;37(2).

http://www.embase.com/search/ results?subaction=viewrecord\&from=export\&id=L631503189

15. Manganaro M, Baldovino S, Besso L, Biancone L, Boero R, Borzumati M, et al. First considerations on the SARS-CoV-2 epidemic in the Dialysis Units of Piedmont and Aosta Valley, Northern Italy. J Nephrol. 2020;40(0123456789):2-4.

https://doi.org/10.1007/s40620-020-00732-1

16. Izzedine H, Jhaveri KD, Perazella MA. COVID-19 therapeutic options for patients with kidney disease. Kidney Int [Internet]. 2020; 97(6):1297-1298. https://doi.org/10.1016/j.kint.2020.03.015.

17. Henry BM, Lippi G. Chronic kidney disease is associated with severe coronavirus disease 2019 (COVID-19) infection. Int Urol Nephrol [Internet]. 2020 Mar;2019(0123456789):9-10. https://doi.org/10.1007/s11255-020-02451-9

18. Rubin R. Finding Ways to Reduce Coronavirus Exposure During Dialysis. JAMA. 2020; 323(20):1993-5. https://doi.org/10.1001/jama.2020.6158

19. Palevsky PM, Radhakrishnan J, Townsend RR, Bakris GL, Forman JP. END-STAGE KIDNEY DISEASE. 2020;2019:1-18.

20. Weiner DE, Watnick SG. Hemodialysis and COVID-19: An Achilles' Heel in the Pandemic Health Care Response in the United States. Kidney Med [Internet]. 2020;20:1-4. https://doi.org/10.1016/j.xkme.2020.03.004

142 Consenso colombiano de expertos sobre recomendaciones informadas en la evidencia para... 
21. Kong L-LI, Yip ILP, Mok W-SG, Chan SYM, Tang M-KC, Wong SWY, et al. Infection Control Precautions for SARS Outbreak in a Tertiary Renal Center in Hong Kong. Dial Transplant [Internet]. 2004;33(4):188-93.

http://www.embase.com/search/ results?subaction=viewrecord\&from=export\&id=L38470775

22. NICE. COVID-19 rapid guideline: dialysis service delivery (NG160). NICE Guidel 2020 [Internet]. 2020;(March). https://www.nice.org.uk/guidance/ng160

23. Wilkie M, Davies S. Peritoneal Dialysis in the time of COVID-19. Perit Dial Int. 2020; 40(4):357-8. https://doi.org/10.1177/0896860820921657

24. Pino M del, Macía M, Sequera P. Documento técnico Recomendaciones para el manejo, prevención y control de COVID-19 en Unidades de Diálisis. 2020;1-13.

25. Policlinico Milan. Preventive measures in haemodialysis centre of Policlinico Milan during COVID-19 Epidemic. 2020:7-8. https://www.theisn.org/images/COVID19-patients-on-HD-in-Policlinico-Milan-Italy-20-03-2020.pdf

26. Christensen L, Rasmussen CS, Benfield T, Franc JM. A Randomized Trial of Instructor-Led Training Versus Video Lesson in Training Health Care Providers in Proper Donning and Doffing of Personal Protective Equipment. Disaster Med Public Health Prep. 2020.

27. Lee J-J, Lin C-Y, Chiu Y-W, Hwang S-J. Take proactive measures for the pandemic COVID-19 infection in the dialysis facilities. J Formos Med Assoc [Internet]. 2020; 119(5): 895-7. https://doi.org/10.1016/j.jfma.2020.03.022

28. Nathan N. Waste Not, Want Not: The Re-Usability of N95 Masks. Anesth Analg. 2020; 131(1):3. https://doi.org/10.1213/ ANE.0000000000004843

29. Francisco ALM De, Canga JLP. Coronavirus y Riñón. Aspectos epidemiológicos del COVID-19. 2020;24. file:///C:/Users/Zona Informatica/ Downloads/nefrologia-dia-287 (1).pdf

30. Kliger AS, Silberzweig J. Mitigating Risk of COVID-19 in Dialysis Facilities. Clin J Am Soc Nephrol [Internet]. 2020;15(5):707-9 https://doi.org/10.2215/CJN.03340320

31. Meijers B, Messa P, Ronco C. Safeguarding the Maintenance Hemodialysis Patient Population during the Coronavirus Disease 19 Pandemic. Blood Purif [Internet]. 2020; https://doi.org/10.1159/000507537

32. International Society for Peritoneal Dialysis (ISPD). Estrategias para el manejo de la pandemia COVID 19 en pacientes en diálisis peritoneal. 2020. https://ispd.org/wp-content/uploads/ISPD-PD-management-in-COVID-19_ESP.pdf

33. Basile C, Combe C, Pizzarelli F, Covic A, Davenport A, Kanbay M, et al. Recommendations for the prevention, mitigation and containment of the emerging SARS-CoV-2 (COVID-19) pandemic in haemodialysis centres. Nephrol Dial Transplant [Internet]. 2020;35(5):737-41. Avaialable from: https://doi.org/10.1093/ndt/gfaa0697

34. Massachusetts General Hospital. Guía de tratamiento COVID-19 Massachussett General Hospital. 2020;1-14.

35. Arenas MD, Villar J, González C, Cao H, Collado S, Crespo M, et al. Manejo de la epidemia por coronavirus SARS-CoV-2 (COVID-19) en unidades de hemodiálisis. Nefrología [Internet]. 2020; 40(3): 258-4. https://doi.org/10.1016/j.nefro.2020.04.001

36. American Society of Nephrology. Recommendations on the care of hospitalized patients with covid-19 and kidney failure requiring renal replacement therapy. 2020;1-5.

37. de Sequera Ortiz P, Quiroga Gili B, de Arriba de la Fuente G, Macia Heras M, Salgueira Lazo M, Del Pino Y Pino MD. Protocol against coronavirus diseases in patients on renal replacement therapy: Dialysis and kidney transplant. Nefrologia. 2020 Apr; 40(3):253-257 https://doi.org/10.1016/j.nefro.2020.03.001

38. Yanyan W, Hongyu L, Xiangbo X, Xingshun G, KexinQi Z. 新型冠状病毒肺炎的临床特 征及治疗结局 : 一项荟萃分析. Chinese J Hepatol. 2020.

39. Ferrey AJ, Choi G, Hanna RM, Chang Y, Tantisattamo E, Ivaturi K, et al. A Case of Novel Coronavirus Disease 19 in a Chronic Hemodialysis Patient Presenting with Gastroenteritis and Developing Severe Pulmonary Disease. Am J Nephrol [Internet]. 2020;51:33742. https://doi.org/10.1159/000507417

40. Fu D, Yang B, Xu J, Mao Z, Zhou C, Xue C, et al. COVID-19 Infection in a Patient with End-Stage Kidney Disease. Nephron [Internet]. 2020 Mar;1-3. http://www.embase.com/search/results?subaction=viewrecord\&from=export\&id=L631474044

41. Rombolà G, Heidempergher M, Pedrini L, Farina M, Aucella F, Messa P, et al. Practical indications for the prevention and management of SARS-CoV-2 in ambulatory dialysis patients: lessons from the first phase of the epidemics in Lombardy. J Nephrol [Internet]. 2020;33(2):193-6. https://doi.org/10.1007/s40620-020-00727-y 
42. Wang R, Liao C, He H, Hu C, Wei Z, Hong Z, et al. COVID-19 in Hemodialysis Patients: A Report of 5 Cases. Am J Kidney Dis [Internet]. 2020;XX(December 2019):2019-21. https://doi.org/10.1053/j.ajkd.2020.03.009

43. Zhang G, Hu C, Luo L, Fang F, Chen Y, Li J, et al. Clinical features and short-term outcomes of 221 patients with COVID-19 in Wuhan, China. J Clin Virol [Internet]. 2020;127(March):104364. https://doi.org/10.1016/j.jcv.2020.104364

44. Chen T, Wu D, Chen H, Yan W, Yang D, Chen G, et al. Clinical characteristics of 113 deceased patients with coronavirus disease 2019: Retrospective study. BMJ. 2020 Mar;368:m1091. https://doi.org/10.1136/bmj.m1091

45. Ikizler TA, Kliger AS. Minimizing the risk of COVID-19 among patients on dialysis. Nat Rev Nephrol [Internet]. 2020;1-3. https://doi.org/10.1038/s41581-020-0280-y

46. Henry BM, de Oliveira MHS, Benoit S, Plebani M, Lippi G. Hematologic, biochemical and immune biomarker abnormalities associated with severe illness and mortality in coronavirus disease 2019 (COVID-19): a meta-analysis. Clin Chem Lab Med. 2020;58(7):1021-8. https://doi.org/10.1515/cclm-2020-0369

47. Alberici F, Delbarba E, Manenti C, Econimo L, Valerio F, Pola A, et al. Management of Patients on Dialysis and With Kidney Transplantation During the SARS-CoV-2 (COVID-19) Pandemic in Brescia, Italy. Kidney Int Reports [Internet]. 2020; https://doi.org/10.1016/ j.ekir,2020.04.001 http://www.embase.com/search/results?subaction=viewrecord\&from=export\&id=L2005633870

48. Berhes M, Fabian A, Laszlo I, Vegh T, Molnar C, Fulesdi B, et al. [Organ replacement therapy and life-supporting treatment modalities in critically ill COVID-19 patients]. Orv Hetil. 2020 Apr;161(17):704-9. https://doi.org/10.1556/650.2020.31813

49. Escher R, Breakey N, Lämmle B. Severe COVID-19 infection associated with endothelial activation. Thromb Res [Internet]. 2020;190(April):62. https://doi.org/10.1016/j.thromres.2020.04.014

50. Zhang Y, Xiao M, Zhang S, Xia P, Cao W, Jiang W, et al. Coagulopathy and Antiphospholipid Antibodies in Patients with Covid-19. Nejm. 2020;382(17). https://doi.org/10.1056/NEJMc2007575

51. Li X, Wang L, Yan S, Yang F, Xiang L, Zhu J, et al. Clinical characteristics of 25 death cases with COVID-19: a retrospective review of medical records in a single medical center, Wuhan, China. Int J Infect Dis [Internet]. 2020 Apr;94:128-32. https://doi.org/10.1016/j.ijid.2020.03.053

52. Karaboyas A, Zee J, Morgenstern H, Nolen JG, Hakim R, Kalantar-zadeh K, et al. Article Understanding the Recent Increase in Ferritin Levels in United States Dialysis Patients?: Potential Impact of Changes in Intravenous Iron and Erythropoiesis- Stimulating Agent Dosing. 2015;10(6).

53. Gubensek J, Lolic M, Ponikvar R, Buturovic-ponikvar J. D-dimer levels in maintenance hemodialysis patients?: High prevalence of positive values also in the group without predisposing diseases. 2016;198-203.

54. Brioni E, Leopaldi D, Magnaghi C, Franchetti R, Granellini E, Pegoraro M, et al. [Covid-19 in patients on dialysis: infection prevention and control strategies]. G Ital Nefrol. 2020 Apr;37(2):2020-vol2.

55. Alberici F, Del Barba E, Manenti C, Econimo L, Valerio F, Pola A, et al. Managing patients in dialysis and with kidney transplant infected with Covid-19. G Ital Nefrol [Internet]. 2020;37(2). http://www.embase.com/search/results?subaction=viewrecord\&from=export\&id=L63150216

56. Wang L, Li X, Chen H, Yan S, Li D, Li Y, et al. Coronavirus Disease 19 Infection Does Not Result in Acute Kidney Injury: An Analysis of 116 Hospitalized Patients from Wuhan, China. Am J Nephrol [Internet]. 2020;51:343-8. https://doi.org/10.1159/000507471

57. Watnick S, McNamara E. On the Frontline of the COVID-19 Outbreak: Keeping Patients on Long-Term Dialysis Safe. Clin J Am Soc Nephrol. 2020;15(5):710-3. https://doi.org/10.2215/cjn.03540320

58. Huang C, Wang Y, Li X, Ren L, Zhao J, Hu Y, et al. Clinical features of patients infected with 2019 novel coronavirus in Wuhan, China. Lancet. 2020;395(10223):497-506. https://doi.org/10.1016/S0140-6736(20)30183-5

59. Liao X, Wang B, Kang Y. Novel coronavirus infection during the 2019-2020 epidemic: preparing intensive care units-the experience in Sichuan Province, China. Intensive Care Med [Internet]. 2020;46(2):357-60. https://doi.org/10.1007/s00134-020-05954-2

60. Asociación Colombiana de Medicina Critica y Cuidado Intensivo (AMCI). Capítulo 3. Ingreso del paciente a UCI. Procedimiento de ingreso y traslado hospitalario. (1). http://www.amci.org.co/images/consenso/Capitulo_3_Ingreso_del_paciente_a_UCI_Proce_ dimiento_de_ingreso_y_traslado_hospitalario.pdf

61. Hospital Brigham Women's. Ethics. COVID-19 Clinical Guidelines. 2020.

144 Consenso colombiano de expertos sobre recomendaciones informadas en la evidencia para... 
62. OPS. Orientación ética para el uso de recursos limitados en los servicios críticos de salud durante la pandemia de COVID-19. PAHO [Internet]. 2020;21(1):1-9. https://doi.org/10.1016/j.solener.2019.02.027\%0Ahttps://www.golder.com/insights/block- caving-a-viable-alternative $/ \% 0 \mathrm{~A} ? ? \bullet$

63. NICE. COVID-19 rapid guideline: critical care in adults. Natl Inst Heal Care Excell. 2020;(March):2020.

64. Vergano M, Bertolini G, Giannini A, Gristina GR, Livigni S, Mistraletti G, et al. SIAARTI recommendations for the allocation of intensive care treatments in exceptional, resource- limited circumstances. Minerva Anestesiol. 2020; 86(5):1-8.

https://doi.org/10.23736/S0375-9393.20.14619-4

65. Asociación Colombiana de Medicina Crítica y Cuidado Intensivo. Capítulo 8. Ética en la atención del paciente COVID-19 La. 2020;1-3.

66. Ministerio de salud y Protección Social. Recomendaciones generales para la toma de decisiones éticas en los servicios de salud durante la pandemia COVID- 19. Minist Salud y Protección Soc - Colomb [Internet]. 2020;1-6. https://www.minsalud.gov.co/ Normatividad_Nuevo/Resolución 1051 de 2016.pdf

67. Sociedad Española de Cuidados Paliativos. Orientaciones sobre el Control sintomático de enfermos graves afectados por la enfermedad Covid 19 y que requieran atención paliativa o se encuentren próximos al final de la vida. 2020;1-8.

68. Sociedad Española de Medicina Intensiva. Recomendaciones éticas para la toma de decisiones en la situación excepcional de crisis por pandemia Covid-19 en las Unidades de Cuidados intensivos. 2020;1-13. https://www.sedar.es/images/site/BIBLIOGRAFIA_COVID-19/UCI/DOC_OSKD_RECOMENDACIONES_ETICAS_TRIAGE_UCI-CRITICOS.pdf

69. Sorbello M, El-Boghdadly K, Di Giacinto I, Cataldo R, Esposito C, Falcetta S, et al. The Italian coronavirus disease 2019 outbreak: recommendations from clinical practice. Anaesthesia. 2020Mar;1-9. https://doi.org/10.1111/anae.15049

70. Huh S. How to train health personnel to protect themselves from SARS-CoV-2 (novel coronavirus) infection when caring for a patient or suspected case. J Educ Eval Health Prof. 2020;17:1-6. https://doi.org/10.3352/jeehp.2020.17.10 


\section{Anexo A. Evaluación calidad de evidencia}

\begin{tabular}{|c|c|c|}
\hline Documento & $\begin{array}{c}\text { Tipo de } \\
\text { documento }\end{array}$ & $\begin{array}{l}\text { Evaluación } \\
\text { de calidad }\end{array}$ \\
\hline $\begin{array}{l}\text { Alberici F, Del Barba E, Manenti C, Econimo L, Valerio F, Pola A, et al. } \\
\text { [Managing patients in dialysis and with kidney transplant infected with } \\
\text { Covid-19]. G Ital Nefrol. 2020 Apr;37(2). }\end{array}$ & Punto de vista & N/A \\
\hline $\begin{array}{l}\text { Alberici F, Delbarba E, Manenti C, Econimo L, Valerio F, Pola A, et al. } \\
\text { Management of Patients on Dialysis and With Kidney Transplantation During } \\
\text { the SARS-CoV-2(COVID-19) Pandemic in Brescia, Italy. Kidney Int Reports } \\
\text { [Internet]. 2020; Available from: } \\
\text { http://www.embase.com/search/results?subaction=viewrecord\&from=expor } \\
\text { t\&id=L2005633870 }\end{array}$ & Punto de vista & N/A \\
\hline $\begin{array}{l}\text { American Society of Nephrology. Recommendations on the care of hospitalized } \\
\text { patients with covid-19 and kidney failure requiring renal } \\
\text { replacement therapy. 2020;1-5. }\end{array}$ & Recomendaciones & N/A \\
\hline $\begin{array}{l}\text { Angel-Korman A, Brosh T, Glick K, Leiba A. [COVID-19, THE KIDNEY } \\
\text { AND HYPERTENSION]. Vol. 159, Harefuah. Israel; 2020. p. 231-4. }\end{array}$ & Resumen & N/A \\
\hline $\begin{array}{l}\text { Arenas MD, Villar J, González C, Cao H, Collado S, Crespo M, et al. } \\
\text { Manejo de la epidemia por coronavirus SARS-CoV-2 (COVID-19) en unidades } \\
\text { de hemodiálisis. Nefrología [Internet]. 2020;2(x x):1-7. Available from: } \\
\text { https://doi.org/10.1016/j.nefro.2020.04.001 }\end{array}$ & Recomendaciones & N/A \\
\hline $\begin{array}{l}\text { Asociación Colombiana de Medicina Critica y Cuidado Intensivo (AMCI). } \\
\text { Capítulo 3. Ingreso del paciente a UCI. Procedimiento de ingreso y traslado } \\
\text { hospitalario.(1). Available from: } \\
\text { http://www.amci.org.co/images/consenso/Capitulo_3_Ingreso_del_paciente } \\
\text { _a_UCI_Proce_dimiento_de_ingreso_y_traslado_hospitalario.pdf }\end{array}$ & Consenso informal & N/A \\
\hline $\begin{array}{l}\text { Asociación Colombiana de Medicina Critica y Cuidado Intensivo. Capítulo } \\
\text { 8. Ética en la atención del paciente COVID-19 La. 2020;1-3. }\end{array}$ & Consenso informal & N/A \\
\hline $\begin{array}{l}\text { Asociación Colombiana de Nefrología e, Hipertensión. Recomendaciones para } \\
\text { el manejo de pacientes portadores de enfermedad renal frente a la } \\
\text { epidemia de coronavirus (COVID-19). 2020;(15). }\end{array}$ & Consenso informal & N/A \\
\hline $\begin{array}{l}\text { Basile C, Combe C, Pizzarelli F, Covic A, Davenport A, Kanbay M, et al. } \\
\text { Recommendations for the prevention, mitigation and containment of the } \\
\text { emerging SARS-CoV-2 (COVID-19) pandemic in haemodialysis centres. } \\
\text { Nephrol Dial Transplant [Internet]. 2020; Available from: } \\
\text { http://www.embase.com/search/results? subaction=viewrecord\&from=expor } \\
\text { t\&id=L631289370 }\end{array}$ & Recomendaciones & N/A \\
\hline $\begin{array}{l}\text { Berhes M, Fabian A, Laszlo I, Vegh T, Molnar C, Fulesdi B, et al. [Organ } \\
\text { replacement therapy and life-supporting treatment modalities in critically ill } \\
\text { COVID-19 patients]. Orv Hetil. } 2020 \text { Apr;161(17):704-9. }\end{array}$ & Punto de vista & N/A \\
\hline $\begin{array}{l}\text { Brioni E, Leopaldi D, Magnaghi C, Franchetti R, Granellini E, Pegoraro M, } \\
\text { et al. [Covid-19 in patients on dialysis: infection prevention and control } \\
\text { strategies]. G Ital Nefrol. } 2020 \mathrm{Apr} ; 37(2) .\end{array}$ & Recomendaciones & N/A \\
\hline $\begin{array}{l}\text { Burgner A, Ikizler TA, Dwyer JP. COVID-19 and the Inpatient Dialysis } \\
\text { Unit: Managing Resources During Contingency Planning Pre-Crisis. Clin J Am } \\
\text { Soc Nephrol. 2020;15(4). }\end{array}$ & Punto de vista & N/A \\
\hline $\begin{array}{l}\text { Chen T, Wu D, Chen H, Yan W, Yang D, Chen G, et al. Clinical } \\
\text { characteristics of } 113 \text { deceased patients with coronavirus disease 2019: } \\
\text { Retrospective study. BMJ. } 2020 \text { Mar;368:m1091. }\end{array}$ & Serie de casos & $\begin{array}{l}\text { Cumple } \\
\text { reporte JBI }\end{array}$ \\
\hline
\end{tabular}




\begin{tabular}{|c|c|c|}
\hline Documento & $\begin{array}{c}\text { Tipo de } \\
\text { documento }\end{array}$ & $\begin{array}{l}\text { Evaluación } \\
\text { de calidad }\end{array}$ \\
\hline $\begin{array}{l}\text { Christensen L, Rasmussen CS, Benfield T, Franc JM. A Randomized Trial of } \\
\text { Instructor-Led Training Versus Video Lesson in Training Health Care } \\
\text { Providers in Proper Donning and Doffing of Personal Protective Equipment. } \\
\text { Disaster Med Public Health Prep. 2020; }\end{array}$ & $\begin{array}{l}\text { Ensayo clínico } \\
\text { aleatorizado }\end{array}$ & $\begin{array}{l}\text { Bajo } \\
\text { riesgo de } \\
\text { sesgo }\end{array}$ \\
\hline $\begin{array}{l}\text { Cuenta de Alto Costo (CAC). Situación de la enfermedad Renal Crónica, } \\
\text { Hipertensión arterial y Diabetes Mellitus en Colombia 2018. 2018; }\end{array}$ & Informe & N/A \\
\hline $\begin{array}{l}\text { de Sequera Ortiz P, Quiroga Gili B, de Arriba de la Fuente G, Macia Heras } \\
\text { M, Salgueira Lazo M, Del Pino Y Pino MD. Protocol against coronavirus } \\
\text { diseases in patients on renal replacement therapy: Dialysis and kidney } \\
\text { transplant. Nefrologia. } 2020 \text { Apr; }\end{array}$ & $\begin{array}{l}\text { Protocolo de } \\
\text { manejo }\end{array}$ & N/A \\
\hline $\begin{array}{l}\text { Dong E, Du H, Gardner L. An interactive web-based dashboard to track } \\
\text { COVID-19 in real time. Lancet Infect Dis [Internet]. 2020;20(5):533-4. } \\
\text { Available from: http://dx.doi.org/10.1016/S1473-3099(20)30120-1 }\end{array}$ & Correspondencia & N/A \\
\hline $\begin{array}{l}\text { Dong J. Estrategias para el manejo de la pandemia COVID } 19 \text { en pacientes } \\
\text { en diálisis peritoneal. International Society for Peritoneal Dialysis (ISPD). 2020; }\end{array}$ & Recomendaciones & N/A \\
\hline $\begin{array}{l}\text { Escher R, Breakey N, Lämmle B. Severe COVID-19 infection associated } \\
\text { with endothelial activation. Thromb Res [Internet]. 2020;190(April):62. } \\
\text { Available from: https://doi.org/10.1016/j.thromres.2020.04.014 }\end{array}$ & Carta al editor & N/A \\
\hline $\begin{array}{l}\text { Ferrey AJ, Choi G, Hanna RM, Chang Y, Tantisattamo E, Ivaturi K, et al. A } \\
\text { Case of Novel Coronavirus Disease } 19 \text { in a Chronic Hemodialysis Patient } \\
\text { Presenting with Gastroenteritis and Developing Severe Pulmonary Disease. Am } \\
\text { J Nephrol [Internet]. 2020; Available from: } \\
\text { http://www.embase.com/search/results?subaction=viewrecord\&from=expor } \\
\text { t\&id=L631577742 }\end{array}$ & Reporte de caso & $\begin{array}{l}\text { Cumple } \\
\text { reporte JBI }\end{array}$ \\
\hline $\begin{array}{l}\text { Francisco ALM De, Canga JLP. Coronavirus y Riñón ASPECTOS } \\
\text { EPIDEMIOLOGICOS DEL COVID-19. 2020;24. }\end{array}$ & Revisión narrativa & Baja calidad \\
\hline $\begin{array}{l}\text { Fu D, Yang B, Xu J, Mao Z, Zhou C, Xue C, et al. COVID-19 Infection in a } \\
\text { Patient with End-Stage Kidney Disease. Nephron [Internet]. } 2020 \text { Mar;1-3. } \\
\text { Available from: } \\
\text { http://www.embase.com/search/results?subaction=viewrecord\&from=expor } \\
\text { t\&id=L631474044 }\end{array}$ & Reporte de caso & $\begin{array}{l}\text { Cumple } \\
\text { reporte JBI }\end{array}$ \\
\hline $\begin{array}{l}\text { Gubensek J, Lolic M, Ponikvar R, Buturovic-ponikvar J. D-dimer levels in } \\
\text { maintenance hemodialysis patients : High prevalence of positive values also } \\
\text { in the group without predisposing diseases. 2016;198-203. }\end{array}$ & $\begin{array}{l}\text { Corte transversal } \\
\text { analítico }\end{array}$ & $\begin{array}{l}\text { Cumple } \\
\text { reporte JBI }\end{array}$ \\
\hline $\begin{array}{l}\text { Haberal M. COVID-19 UPDATE. Vol. 18, Experimental and clinical } \\
\text { transplantation : official journal of the Middle East Society for Organ } \\
\text { Transplantation. Turkey; 2020. p. 139-40. }\end{array}$ & Editorial & N/A \\
\hline $\begin{array}{l}\text { Henry BM, de Oliveira MHS, Benoit S, Plebani M, Lippi G. Hematologic, } \\
\text { biochemical and immune biomarker abnormalities associated with severe illness } \\
\text { and mortality in coronavirus disease } 2019 \text { (COVID-19): a meta- analysis. Clin } \\
\text { Chem Lab Med. 2020;0(0). }\end{array}$ & $\begin{array}{l}\text { Revisión } \\
\text { sistemática }\end{array}$ & Baja \\
\hline $\begin{array}{l}\text { Henry BM, Lippi G. Chronic kidney disease is associated with severe } \\
\text { coronavirus disease 2019 (COVID-19) infection. Int Urol Nephrol } \\
\text { [Internet]. 2020 Mar;2019(0123456789):9-10. Available from: } \\
\text { https://doi.org/10.1007/s11255-020-02451-9 }\end{array}$ & Carta al editor & N/A \\
\hline Hospital Brigham Women's. Ethics. COVID-19 Clinical Guidelines. 2020 & Recomendaciones & N/A \\
\hline
\end{tabular}


Huang C, Wang Y, Li X, Ren L, Zhao J, Hu Y, et al. Clinical features of patients infected with 2019 novel coronavirus in Wuhan, China. Lancet. 2020;395(10223):497-506.

Huh S. How to train health personnel to protect themselves from SARSCoV-2 (novel coronavirus) infection when caring for a patient or suspected case. J Educ Eval Health Prof. 2020;17:1-6.

Ikizler T. COVID-19 and Dialysis Units: What Do We Know Now and What Should We Do? Am J Kidney Dis [Internet]. 2020; Available from: http://www.embase.com/search/results?subaction=viewrecord\&from=expor t\&id=L2005534240

Ikizler TA, Kliger AS. Minimizing the risk of COVID-19 among patients on dialysis. Nat Rev Nephrol [Internet]. 2020;1-3. Available from: http://dx.doi.org/10.1038/s41581-020-0280-y

Instituto de Evaluación Tecnológica en Salud, Asociación colombiana de Infectología. Consenso colombiano de atención, diagnóstico y manejo de la infección por SARS-COV-2/COVID-19. Rev Colomb infectología. 2020;24:47. Izzedine H, Jhaveri KD, Perazella MA. COVID-19 therapeutic options for patients with kidney disease. Kidney Int [Internet]. 2020; Available from: http://www.embase.com/search/results? subaction=viewrecord\&from=expor t\&id=L2005613343

Joanna Briggs Institute. The Joanna Briggs Institute Scientific Writer Handbook. 2018;29. Available from: http://joannabriggswebdev.org/assets/docs/scientificWriters/JBI Scientific Writer Handbook_July 2018.pdf

Karaboyas A, Zee J, Morgenstern H, Nolen JG, Hakim R, Kalantar-zadeh $\mathrm{K}$, et al. Article Understanding the Recent Increase in Ferritin Levels in United States Dialysis Patients : Potential Impact of Changes in Intravenous Iron and Erythropoiesis- Stimulating Agent Dosing. 2015;10(6).

Kliger AS, Silberzweig J. Mitigating Risk of COVID-19 in Dialysis Facilities. Clin J Am Soc Nephrol [Internet]. 2020; Available from: http://www.embase.com/search/results?subaction=viewrecord\&from=expor t\&id=L631300155

Kong L-LI, Yip ILP, Mok W-SG, Chan SYM, Tang M-KC, Wong SWY, et al. Infection Control Precautions for SARS Outbreak in a Tertiary Renal Center in Hong Kong. Dial Transplant [Internet]. 2004;33(4):188-93. Available from: http://www.embase.com/search/results?subaction=viewrecord\&from=expor t\&id=L38470775

Lee J-J, Lin C-Y, Chiu Y-W, Hwang S-J. Take proactive measures for the pandemic COVID-19 infection in the dialysis facilities. J Formos Med Assoc [Internet]. 2020; Available from: http://www.embase.com/search/results?subaction=viewrecord\&from=expor t\&id=L2005548218

Li X, Wang L, Yan S, Yang F, Xiang L, Zhu J, et al. Clinical characteristics of 25 death cases with COVID-19: a retrospective review of medical records in a single medical center, Wuhan, China. Int J Infect Dis [Internet]. 2020 Apr;94:128-32. Available from: https://doi.org/10.1016/j.ijid.2020.03.053

148 Consenso colombiano de expertos sobre recomendaciones informadas en la evidencia para... 


\begin{tabular}{|c|c|c|}
\hline Documento & $\begin{array}{c}\text { Tipo de } \\
\text { documento }\end{array}$ & $\begin{array}{l}\text { Evaluación } \\
\text { de calidad }\end{array}$ \\
\hline $\begin{array}{l}\text { Liao X, Wang B, Kang Y. Novel coronavirus infection during the 2019- } \\
2020 \text { epidemic: preparing intensive care units - the experience in Sichuan } \\
\text { Province, China. Intensive Care Med [Internet]. 2020;46(2):357-60. Available } \\
\text { from: https://doi.org/10.1007/s00134-020-05954-2 }\end{array}$ & Recomendaciones & N/A \\
\hline $\begin{array}{l}\text { Manganaro M, Baldovino S, Besso L, Biancone L, Boero R, Borzumati M, et al. } \\
\text { First considerations on the SARS-CoV-2 epidemic in the Dialysis Units of Pied- } \\
\text { mont and Aosta Valley, Northern Italy. J Nephrol. 2020;40(0123456789):2-4. }\end{array}$ & Editorial & N/A \\
\hline $\begin{array}{l}\text { Massachusetts General Hospital. Guia de tratamiento COVID-19 } \\
\text { Massachussett General Hospital. 2020;1-14. }\end{array}$ & Recomendaciones & N/A \\
\hline $\begin{array}{l}\text { Meijers B, Messa P, Ronco C. Safeguarding the Maintenance Hemodialysis } \\
\text { Patient Population during the Coronavirus Disease } 19 \text { Pandemic. Blood Purif } \\
\text { [Internet]. 2020; Available from: } \\
\text { http://www.embase.com/search/results?subaction=viewrecord\&from=expor } \\
\text { t\&id=L631577659 }\end{array}$ & Editorial & N/A \\
\hline $\begin{array}{l}\text { Ministerio de salud y Protección Social. Recomendaciones generales para la } \\
\text { toma de decisiones éticas en los servicios de salud durante la pandemia } \\
\text { COVID- 19. Minist Salud y Protección Soc - Colomb [Internet]. 2020;1-6. } \\
\text { Available from: https://www.minsalud.gov.co/Normatividad_Nuevo/Resolución } \\
\text { 1051 de 2016.pdf }\end{array}$ & Recomendaciones & N/A \\
\hline $\begin{array}{l}\text { Nathan N. Waste Not, Want Not: The Re-Usability of N95 Masks. Anesth } \\
\text { Analg. 2020;1-3. }\end{array}$ & Infografía & N/A \\
\hline $\begin{array}{l}\text { NICE. COVID-19 rapid guideline: critical care in adults. Natl Inst Heal } \\
\text { Care Excell. 2020;(March):2020. }\end{array}$ & Guía rápida & Moderada \\
\hline $\begin{array}{l}\text { NICE. COVID-19 rapid guideline: dialysis service delivery (NG160). NICE } \\
\text { Guidel } 2020 \text { [Internet]. 2020;(March). Available from: } \\
\text { https://www.nice.org.uk/guidance/ng160 }\end{array}$ & Guía rápida & Moderada \\
\hline $\begin{array}{l}\text { OPS. Orientación ética para el uso de recursos limitados en los servicios críticos } \\
\text { de salud durante la pandemia de COVID-19. PAHO [Internet]. 2020;21(1):1-9. } \\
\text { Available from: } \\
\text { https://doi.org/10.1016/j.solener.2019.02.027\%0Ahttps://www.golder.com/i } \\
\text { nsights/block-caving-a-viable-alternative/\%0A??? }\end{array}$ & Recomendaciones & N/A \\
\hline $\begin{array}{l}\text { Palevsky PM, Radhakrishnan J, Townsend RR, Bakris GL, Forman JP. } \\
\text { END-STAGE KIDNEY DISEASE. 2020;2019:1-18. }\end{array}$ & Recomendaciones & N/A \\
\hline $\begin{array}{l}\text { Perico L, Benigni A, Remuzzi G. Should covid-19 concern nephrologists? } \\
\text { why and to what extent? The emerging impasse of angiotensin blockade. } \\
\text { Nephron [Internet]. 2020; Available from: }\end{array}$ & Revisión narrativa & Baja calidad \\
\hline $\begin{array}{l}\text { http://www.embase.com/search/results?subaction=viewrecord\&from=expor } \\
\text { t\&id=L631369382 }\end{array}$ & & \\
\hline $\begin{array}{l}\text { Pino M del, Macía M, Sequera P. Documento técnico Recomendaciones para el } \\
\text { manejo, prevención y control de COVID-19 en Unidades de Diálisis. 2020;1- } \\
13 .\end{array}$ & Recomendaciones & N/A \\
\hline $\begin{array}{l}\text { Policlinico Milan. Preventive measures in haemodialysis centre of Policlinico } \\
\text { Milan during COVID-19 Epidemic. :7-8. }\end{array}$ & Editorial & N/A \\
\hline
\end{tabular}




\begin{tabular}{|c|c|c|}
\hline Documento & $\begin{array}{c}\text { Tipo de } \\
\text { documento }\end{array}$ & $\begin{array}{l}\text { Evaluación } \\
\text { de calidad }\end{array}$ \\
\hline $\begin{array}{l}\text { Rombolà G, Heidempergher M, Pedrini L, Farina M, Aucella F, Messa P, et al. } \\
\text { Practical indications for the prevention and management of SARS-CoV-2 in } \\
\text { ambulatory dialysis patients: lessons from the first phase of the epidemics in } \\
\text { Lombardy. J Nephrol [Internet]. 2020;33(2):193-6. Available from: } \\
\text { https://doi.org/10.1007/s40620-020-00727-y }\end{array}$ & Editorial & N/A \\
\hline $\begin{array}{l}\text { Rubin R. Finding Ways to Reduce Coronavirus Exposure During Dialysis. } \\
\text { Jama. 2020;1-3. }\end{array}$ & Punto de vista & N/A \\
\hline $\begin{array}{l}\text { Scarpioni R, Manini A, Valsania T, De Amicis S, Albertazzi V, Melfa L, et al. } \\
\text { Covid-19 and its impact on nephropathic patients: the experience at Ospedale } \\
\text { "Guglielmo da Saliceto" in Piacenza. G Ital Nefrol [Internet]. 2020;37(2). } \\
\text { Available from: } \\
\text { http://www.embase.com/search/results?subaction=viewrecord\&from=expor } \\
\text { t\&id=L631503189 }\end{array}$ & Editorial & N/A \\
\hline $\begin{array}{l}\text { Sociedad Española de Cuidados Paliativos. Orientaciones sobre el Control } \\
\text { sintomático de enfermos graves afectados por la enfermedad Covid } 19 \text { y que } \\
\text { requieran atención paliativa o se encuentren próximos al final de la vida. } \\
\text { 2020;1-8. }\end{array}$ & Recomendaciones & N/A \\
\hline $\begin{array}{l}\text { Sociedad Española de Medicina Intensiva. Recomendaciones éticas para la toma } \\
\text { de decisiones en la situación excepcional de crisis por pandemia Covid-19 en las } \\
\text { Unidades de Cuidados intensivos. 2020;1-13. Available from: } \\
\text { https://www.sedar.es/images/site/BIBLIOGRAFIA_COVID- } \\
\text { 19/UCI/DOC_OSKD_RECOMENDACIONES_ETICAS_TRIAGE_UCI- } \\
\text { CRITICOS.pdf }\end{array}$ & Recomendaciones & N/A \\
\hline $\begin{array}{l}\text { Sorbello M, El-Boghdadly K, Di Giacinto I, Cataldo R, Esposito C, Falcetta S, } \\
\text { et al. The Italian coronavirus disease } 2019 \text { outbreak: recommendations from } \\
\text { clinical practice. Anaesthesia. 2020;(March):1-9. }\end{array}$ & Perspectiva & N/A \\
\hline $\begin{array}{l}\text { Tang B, Li S, Xiong Y, Tian M, Yu J, Xu L, et al. Coronavirus Disease } 2019 \\
\text { (COVID-19) Pneumonia in a Hemodialysis Patient. Kidney Med [Internet]. } \\
\text { 2020; Available from: } \\
\text { http://www.embase.com/search/results?subaction=viewrecord\&from=expor } \\
\text { t\&id=L2005598555 }\end{array}$ & Reporte de caso & $\begin{array}{l}\text { Cumple } \\
\text { reporte JBI }\end{array}$ \\
\hline $\begin{array}{l}\text { Vergano M, Bertolini G, Giannini A, Gristina GR, Livigni S, Mistraletti G, et al. } \\
\text { SIAARTI recommendations for the allocation of intensive care treatments in } \\
\text { exceptional, resource-limited circumstances. Minerva Anestesiol. 2020;1-8. }\end{array}$ & Recomendaciones & N/A \\
\hline $\begin{array}{l}\text { Wang L, Li X, Chen H, Yan S, Li D, Li Y, et al. Coronavirus Disease } 19 \\
\text { Infection Does Not Result in Acute Kidney Injury: An Analysis of } 116 \\
\text { Hospitalized Patients from Wuhan, China. Am J Nephrol [Internet]. } \\
\text { 2020;1-6. Available from: } \\
\text { http://www.embase.com/search/results?subaction=viewrecord\&from=expor } \\
\text { t\&id=L631417498 }\end{array}$ & Serie de casos & Moderada \\
\hline $\begin{array}{l}\text { Wang R, Liao C, He H, Hu C, Wei Z, Hong Z, et al. COVID-19 in } \\
\text { Hemodialysis Patients: A Report of 5 Cases. Am J Kidney Dis [Internet]. } \\
\text { 2020;XX(December 2019):2019-21. Available from: } \\
\text { https://doi.org/10.1053/j.ajkd.2020.03.009 }\end{array}$ & Reporte de caso & $\begin{array}{c}\text { Cumple } \\
\text { reporte JBI }\end{array}$ \\
\hline
\end{tabular}




\begin{tabular}{|c|c|c|}
\hline Documento & $\begin{array}{l}\text { Tipo de } \\
\text { documento }\end{array}$ & $\begin{array}{l}\text { Evaluación } \\
\text { de calidad }\end{array}$ \\
\hline $\begin{array}{l}\text { Watnick S, McNamara E. On the Frontline of the COVID-19 Outbreak: } \\
\text { Keeping Patients on Long-Term Dialysis Safe. Clin J Am Soc Nephrol. } \\
\text { 2020;(Figure 1):2-5. }\end{array}$ & Perspectiva & N/A \\
\hline $\begin{array}{l}\text { Weiner DE, Watnick SG. Hemodialysis and COVID-19: An Achilles' Heel } \\
\text { in the Pandemic Health Care Response in the United States. Kidney Med } \\
\text { [Internet]. 2020;XX:1-4. Available from: } \\
\text { https://doi.org/10.1016/j.xkme.2020.03.004 }\end{array}$ & Editorial & N/A \\
\hline $\begin{array}{l}\text { Wilkie M, Davies S. Peritoneal Dialysis in the time of COVID-19. Perit Dial } \\
\text { Int. 2020;896860820921657. }\end{array}$ & Comentario & N/A \\
\hline $\begin{array}{l}\text { Yan Zhang, M.D. Meng Xiao, M.Sc. Shulan Zhang, M.D. Peng Xia MD, Wei } \\
\text { Cao MD, Wei Jiang MD, Huan Chen MD, Xin Ding MD, Hua Zhao, M.D. } \\
\text { Hongmin Zhang MD. C or r e sp ondence Coagulopathy and Antiphospholipid } \\
\text { Antibodies in Patients with Covid-19. Nejm. 2020;38(1):1-3. }\end{array}$ & Correspondencia & N/A \\
\hline $\begin{array}{l}\text { Yanyan W, Hongyu L, Xiangbo X, Xingshun G, KexinQi Z. 新型冠状病毒 } \\
\text { 肺炎的临床特征及治疗结局：一项荟萃分析. Chinese J Hepatol. 2020; }\end{array}$ & Reporte de caso & $\begin{array}{c}\text { Cumple } \\
\text { reporte JBI }\end{array}$ \\
\hline $\begin{array}{l}\text { Zhang G, Hu C, Luo L, Fang F, Chen Y, Li J, et al. Clinical features and short- } \\
\text { term outcomes of } 221 \text { patients with COVID-19 in Wuhan, China. J Clin Virol } \\
\text { [Internet]. 2020;127(March):104364. Available from: } \\
\text { https://doi.org/10.1016/j.jcv.2020.104364 }\end{array}$ & Serie de casos & $\begin{array}{l}\text { Cumple } \\
\text { reporte JBI }\end{array}$ \\
\hline $\begin{array}{l}\text { Zhou F, Yu T, Du R, Fan G, Liu Y, Liu Z, et al. Clinical course and risk factors } \\
\text { for mortality of adult in patients with COVID-19 in Wuhan, China: a } \\
\text { retrospective cohort study. Lancet [Internet]. 2020;395(10229):1054-62. } \\
\text { Available from: http://dx.doi.org/10.1016/S0140-6736(20)30566-3 }\end{array}$ & Estudio de cohorte & Moderada \\
\hline
\end{tabular}




\section{Anexo B. Resultados consulta}

\begin{tabular}{|c|c|}
\hline Recomendación & $\begin{array}{c}\text { Resultado } \\
\text { consulta } \\
(\%)\end{array}$ \\
\hline $\begin{array}{l}\text { Se recomienda que: [Las unidades renales y de diálisis dispongan de carteleras y medios para informar } \\
\text { a pacientes, familiares y personal de salud sobre COVID-19.] }\end{array}$ & 100 \\
\hline $\begin{array}{l}\text { Se recomienda que: [Pacientes, familiares, visitantes y personal de las unidades reciban información } \\
\text { sobre la enfermedad COVID-19, forma de contagio y síntomas.] }\end{array}$ & 100 \\
\hline $\begin{array}{l}\text { Se recomienda que: [La unidad divulgue información del lavado de manos respecto a frecuencia y } \\
\text { técnica correcta de realización.] }\end{array}$ & 100 \\
\hline $\begin{array}{l}\text { Se recomienda que: [La unidad divulgue información acerca de la importancia del uso adecuado y } \\
\text { racional de elementos de protección personal, específicamente del frecuente y correcto lavado de } \\
\text { manos, distanciamiento social y uso de mascarillas para pacientes y familiares.] }\end{array}$ & 100 \\
\hline $\begin{array}{l}\text { Se recomienda que: [Los pacientes conozcan medios de contacto de la unidad renal, en caso en que } \\
\text { requieran consultar información o notificar sintomatología antes de presentarse en la unidad.] }\end{array}$ & 95 \\
\hline $\begin{array}{l}\text { Se recomienda que: [Todos los pacientes y familiares usen mascarilla quirúrgica durante su estancia en } \\
\text { la unidad.] }\end{array}$ & 100 \\
\hline Se recomienda que: [El personal de salud use EPP para el desempeño seguro de sus funciones.] & 100 \\
\hline $\begin{array}{l}\text { Se recomienda que: [El personal de salud de las unidades sea capacitado para el uso adecuado y } \\
\text { racional de EPP.] }\end{array}$ & 100 \\
\hline $\begin{array}{l}\text { Se recomienda que: [El personal de salud de las unidades use mascarilla quirúrgica durante su } \\
\text { permanencia en la unidad.] }\end{array}$ & 98 \\
\hline $\begin{array}{l}\text { Se recomienda que: [El personal dedicado a hemodiálisis use EPP de manera estricta: mascarilla } \\
\text { quirúrgica, guantes, protectores oculares como caretas o monogafas y gorro, batas antifluido durante la } \\
\text { conexión, la desconexión y la asistencia del paciente.] }\end{array}$ & 95 \\
\hline $\begin{array}{l}\text { Se recomienda que: [El equipo involucrado en la atención directa de pacientes con sospecha o } \\
\text { confirmación de COVID-19 utilice respirador N95 o nivel superior, de acuerdo con la disponibilidad } \\
\text { del centro o unidad de diálisis. En tiempos de escasez, se debe optimizar la disponibilidad del recurso } \\
\text { para situaciones donde la protección respiratoria es prioritaria, como en la realización de } \\
\text { procedimientos con generación de aerosoles en pacientes con sospecha o confirmación de COVID-19.] }\end{array}$ & 97 \\
\hline $\begin{array}{l}\text { Se recomienda que: [El personal de limpieza y desinfección use los EPP de acuerdo con la } \\
\text { indicación de sus actividades.] }\end{array}$ & 100 \\
\hline Se recomienda que: [El uso de EPP se acompañe de higiene de manos.] & 100 \\
\hline $\begin{array}{l}\text { Se recomienda que: [El personal de salud de las unidades participe en la generación de programas de } \\
\text { educación, alfabetización en salud y comunicación efectiva sobre el uso adecuado y racional de EPP, } \\
\text { utilizando diferentes didácticas a partir de los lineamientos informados en evidencia: videos, } \\
\text { encuentros con expertos, simulacros, grupos focales, mentorías, infografías, además de la } \\
\text { implementación de sistemas de evaluación y seguimiento a la adherencia de las recomendaciones.] }\end{array}$ & 100 \\
\hline $\begin{array}{l}\text { Se recomienda que: [Los equipos de salud cumplan de manera estricta el lavado de manos según lo } \\
\text { estipulado en los protocolos de bioseguridad, enfatizando los } 5 \text { momentos y los } 10 \text { pasos, durante } 20 \text { a } \\
40 \text { segundos, además del uso frecuente de alcohol gel.] }\end{array}$ & 100 \\
\hline No se recomienda: [El uso de tapabocas de tela para evitar propagación desde la fuente.] & 93 \\
\hline $\begin{array}{l}\text { Se recomienda que: [El nefrólogo realice análisis de riesgo-beneficio respecto a la tamización de los } \\
\text { pacientes en diálisis; cada caso deberá ser evaluado de manera independiente.] }\end{array}$ & 95 \\
\hline $\begin{array}{l}\text { Se recomienda que: [En pacientes sintomáticos y sospechosos se realice la prueba RT-PCR antes de la } \\
\text { diálisis; en el caso de diálisis en el hogar se recomienda tamizar pacientes y familiares sintomáticos.] }\end{array}$ & 91 \\
\hline $\begin{array}{l}\text { Se recomienda que: [El personal de salud sintomático o involucrado en atención de pacientes sospechosos } \\
\text { o confirmados nuevos se realice la prueba RT-PCR.] }\end{array}$ & 91 \\
\hline
\end{tabular}

152 Consenso colombiano de expertos sobre recomendaciones informadas en la evidencia para... 


\section{Continuación ANEXO B}

\begin{tabular}{|c|c|}
\hline Recomendación & $\begin{array}{l}\text { Resultado } \\
\text { consulta } \\
(\%)\end{array}$ \\
\hline $\begin{array}{l}\text { Se recomienda que: [Las unidades establezcan protocolo de pre-triage o clasificación de } \\
\text { pacientes.] }\end{array}$ & 100 \\
\hline $\begin{array}{l}\text { Se recomienda: [Implementar medidas de triage previo ingreso del paciente a la unidad; por ejemplo, } \\
\text { llamada el día antes de la sesión de diálisis.] }\end{array}$ & 93 \\
\hline $\begin{array}{l}\text { Se recomienda que: [La clasificación de pacientes incluya consulta de síntomas, contacto cercano con } \\
\text { personas sospechosas o confirmadas, y los criterios de evaluación epidemiológica según la } \\
\text { normatividad vigente.] }\end{array}$ & 100 \\
\hline $\begin{array}{l}\text { Se recomienda que: [Pacientes y personal sean capacitados en la toma de temperatura } 30 \text { minutos } \\
\text { antes de su desplazamiento hacia la unidad.] }\end{array}$ & 93 \\
\hline $\begin{array}{l}\text { Se recomienda que: [Pacientes sean instruidos en la identificación de síntomas y el reporte a la unidad } \\
\text { antes de presentarse.] }\end{array}$ & 100 \\
\hline $\begin{array}{l}\text { Se recomienda que: [Antes del ingreso a la unidad todos los pacientes sean valorados en busca de } \\
\text { síntomas tanto respiratorios como no respiratorios, teniendo particular cuidado de evaluar cuadros } \\
\text { clínicos atípicos propios de pacientes adultos mayores, multimorbidos o inmunosuprimidos, tales como } \\
\text { síndromes geriátricos, delirium, trastornos cognitivos, diarrea, disgeusia, anosmia, diarrea, } \\
\text { osteomialgias, déficit neurológico, agudización de neuropatías, entre otros.] }\end{array}$ & 98 \\
\hline $\begin{array}{l}\text { Se recomienda: [Incluir dentro de la evaluación de pacientes sintomáticos la aplicación de puntajes de } \\
\text { gravedad como el Quick SOFA y NEWS COVID, con el fin de determinar de manera precoz el riesgo } \\
\text { de progresión y necesidad de traslado a urgencias.] }\end{array}$ & 98 \\
\hline Se recomienda que: [Todo el personal que ingresa a la unidad sea valorado en busca de sintomatología.] & 98 \\
\hline $\begin{array}{l}\text { Se recomienda que: [Pacientes y personal con temperatura superior a } 38{ }^{\circ} \mathrm{C} \text { o sintomatología sugestiva } \\
\text { de COVID-19 sean evaluados por el nefrólogo, para priorizar diagnóstico de la infección, aislamiento y } \\
\text { prevención de la transmisión en centros o unidades renales.] }\end{array}$ & 71 \\
\hline Se recomienda que: [Pacientes con factores de mal pronóstico sean remitidos al servicio de urgencias.] & 91 \\
\hline $\begin{array}{l}\text { Se recomienda: [Tener en cuenta la clasificación de pacientes: sospechoso, COVID-19 positivo y } \\
\text { COVID-19 negativo para la gestión de la agenda y realización de la diálisis.] }\end{array}$ & 100 \\
\hline Se recomienda: [Realizar seguimiento de pacientes para identificar cambios en la clasificación.] & 100 \\
\hline $\begin{array}{l}\text { Se recomienda: [Evitar la remisión de pacientes que no presentan síntomas de alarma para evitar } \\
\text { congestionar los servicios de urgencias y exponer al paciente a visitas con alto riesgo de contagio.] }\end{array}$ & 98 \\
\hline $\begin{array}{l}\text { En caso de [No tener capacidad instalada para diálisis aisladas, se recomienda generar tres turnos } \\
\text { diferentes que correspondan a la clasificación de los pacientes o dializar a los pacientes sospechosos o } \\
\text { COVID-19 positivos en el último turno del día y en las últimas estaciones con menor flujo de } \\
\text { personas.] }\end{array}$ & 95 \\
\hline $\begin{array}{l}\text { Se recomienda que: [Pacientes sospechosos y confirmados para COVID-19 tengan aislamiento estricto } \\
\text { en el hogar y solo se desplacen hacia la unidad de diálisis para cumplir con su programación, } \\
\text { manteniendo las precauciones de distanciamiento social y comportamiento en la comunidad.] }\end{array}$ & 98 \\
\hline $\begin{array}{l}\text { Se recomienda: [En pacientes sospechosos o Covid-19 positivo extremar medidas de bioseguridad, para } \\
\text { evitar propagación en la unidad.] }\end{array}$ & 98 \\
\hline $\begin{array}{l}\text { Se recomienda: [Restringir contacto estrecho entre pacientes confirmados COVID-19 con otros } \\
\text { pacientes y con personal de salud.] }\end{array}$ & 100 \\
\hline Se recomienda: [Restringir acceso a áreas comunes por parte de pacientes COVID-19 positivos.] & 100 \\
\hline $\begin{array}{l}\text { Se recomienda: [Evitar el tránsito de pacientes COVID-19 positivo por las instalaciones de la } \\
\text { unidad.] }\end{array}$ & 98 \\
\hline $\begin{array}{l}\text { Se recomienda que: [Pacientes sospechosos sean dializados en áreas o estaciones aisladas en la m } \\
\text { de lo posible. La misma recomendación aplica para pacientes COVID-19 positivo.] }\end{array}$ & 98 \\
\hline
\end{tabular}




\section{Continuación ANEXO B}

\begin{tabular}{|c|c|}
\hline Recomendación & $\begin{array}{c}\text { Resultado } \\
\text { consulta } \\
(\%)\end{array}$ \\
\hline $\begin{array}{l}\text { Se recomienda que: [Pacientes hospitalizados con necesidad de terapia de reemplazo renal sean } \\
\text { dializados dentro de la habitación o área aislada con plantas de agua portátiles.] }\end{array}$ & 95 \\
\hline $\begin{array}{l}\text { Se recomienda: [Llevar registro de personal sanitario en contacto con pacientes sospechosos o COVID- } \\
19 \text { positivos.] }\end{array}$ & 100 \\
\hline No se recomienda: [Integrar pacientes con diferentes diagnósticos respiratorios.] & 95 \\
\hline $\begin{array}{l}\text { Se recomienda que: [Pacientes que requieren asistir a las unidades de diálisis realicen sus } \\
\text { desplazamientos en vehículo privado en la medida de las posibilidades.] }\end{array}$ & 98 \\
\hline Se recomienda: [Evitar el uso de transporte público entre el hogar y la unidad de diálisis.] & 98 \\
\hline $\begin{array}{l}\text { Se recomienda que: [Pacientes COVID-19 positivo con requerimiento de diálisis sean } \\
\text { transportados en vehículos destinados para pacientes COVID-19.] }\end{array}$ & 100 \\
\hline $\begin{array}{l}\text { Se recomienda que: [Todos los ocupantes del vehículo usen mascarillaquirúrgica durante el } \\
\text { desplazamiento.] }\end{array}$ & 98 \\
\hline $\begin{array}{l}\text { Se recomienda que: [El personal encargado del transporte de pacientes indague por la presencia de } \\
\text { síntomas.] }\end{array}$ & 95 \\
\hline $\begin{array}{l}\text { Se recomienda que: [Los vehículos que transportan pacientes de diálisis sean desinfectados al finalizar } \\
\text { el recorrido.] }\end{array}$ & 98 \\
\hline $\begin{array}{l}\text { Se recomienda que: [Las unidades continúen con el protocolo de limpieza y desinfección que realizan } \\
\text { habitualmente.] }\end{array}$ & 93 \\
\hline $\begin{array}{l}\text { Se recomienda que: [El personal encargado de la limpieza y la desinfección sea reforzado e instruido } \\
\text { en la limpieza de superficies susceptibles de depósito del virus.] }\end{array}$ & 100 \\
\hline $\begin{array}{l}\text { Se recomienda que: [La máquina de diálisis empleada en paciente COVID-19 positivo sea desinfectada } \\
\text { con hipoclorito de sodio de acuerdo a los protocolos de limpieza y desinfección terminal antes y } \\
\text { después de su utilización.] }\end{array}$ & 100 \\
\hline $\begin{array}{l}\text { Se recomienda: [El uso de soluciones de hipoclorito sódico con una concentración al 0,1\%, etanol al } 62- \\
71 \% \text { o peróxido de hidrógeno al 0,5\% para la desactivación del virus.] }\end{array}$ & 100 \\
\hline $\begin{array}{l}\text { Se recomienda que: [El material objeto de reprocesamiento sea transportado siguiendo las } \\
\text { recomendaciones habituales acerca de contenedores cerrados.] }\end{array}$ & 98 \\
\hline $\begin{array}{l}\text { Se recomienda: [El adecuado proceso de eliminación de desechos, colocando etiquetas que } \\
\text { correspondan a la clasificación del residuo.] }\end{array}$ & 100 \\
\hline $\begin{array}{l}\text { Se recomienda: [Gestión del personal de salud disponible para diálisis, llevando un registro del } \\
\text { personal y contacto con pacientes sospechosos o COVID-19 positivos.] }\end{array}$ & 98 \\
\hline $\begin{array}{l}\text { Se recomienda: [Llevar un registro estricto de requerimientos y disponibilidad de EPP y todos los } \\
\text { recursos necesarios para garantizar las normas de bioseguridad. Establecer estrategias para predecir el } \\
\text { requerimiento según las tendencias de uso, y anticiparse al desabastecimiento.] }\end{array}$ & 100 \\
\hline Se recomienda: [Establecer protocolos de ingreso y estancia en las unidades de diálisis.] & 100 \\
\hline Se recomienda: [Evitar aglomeración de pacientes en las entradas de la unidad.] & 100 \\
\hline $\begin{array}{l}\text { Se recomienda que: [Los pacientes esperen afuera la indicación de ingreso a través de llamada, mensaje } \\
\text { de texto o WhatsApp.] }\end{array}$ & 89 \\
\hline $\begin{array}{l}\text { Se recomienda: [Colocar dispensadores con preparados de base alcohólica para la higiene de manos, } \\
\text { pañuelos desechables para la higiene respiratoria y contenedores de residuos con bolsa plástica y tapa de } \\
\text { apertura con pedal para su eliminación en la sala de espera y de procedimientos.] }\end{array}$ & 98 \\
\hline
\end{tabular}

154 Consenso colombiano de expertos sobre recomendaciones informadas en la evidencia para... 


\begin{tabular}{|c|c|}
\hline Recomendación & $\begin{array}{l}\text { Resultado } \\
\text { consulta } \\
(\%)\end{array}$ \\
\hline Se recomienda: [El lavado de manos de pacientes al ingreso a la unidad.] & 100 \\
\hline $\begin{array}{l}\text { Se recomienda que: [Mientras los pacientes se encuentren en la sala de espera debe existir una distancia en } \\
\text { todas las direcciones mínima de dos metros.] }\end{array}$ & 100 \\
\hline $\begin{array}{l}\text { Se recomienda: [Establecer rutas de movilización unidireccionales para evitar el contacto estrecho o } \\
\text { choque.] }\end{array}$ & 100 \\
\hline $\begin{array}{l}\text { Se recomienda: [Tiempos de permanencia en la unidad restringidos a los procedimientos. Esta reco- } \\
\text { mendación aplica para el personal de salud en salas aisladas o en contacto con pacientes COVID-19.] }\end{array}$ & 100 \\
\hline $\begin{array}{l}\text { Se recomienda: [Establecer estaciones aisladas para pacientes sospechosos y COVID-19 positivos; en } \\
\text { caso de que no sean posibles salas aisladas, las estaciones deben estar distanciadas al menos por dos } \\
\text { metros.] }\end{array}$ & 98 \\
\hline $\begin{array}{l}\text { Se recomienda: [Seguir técnicas de reemplazo renal establecidas y respecto a las cuales el personal } \\
\text { esté capacitado y familiarizado.] }\end{array}$ & 100 \\
\hline Se recomienda: [Evitar que el personal en formación entre en contacto con pacientes COVID-19.] & 95 \\
\hline $\begin{array}{l}\text { Se recomienda que: [Las salas de espera y de procedimientos tengan dispositivos de ventilación para } \\
\text { eliminar partículas, de acuerdo con la disponibilidad de recursos.] }\end{array}$ & 100 \\
\hline $\begin{array}{l}\text { Se recomienda: [Realizar el diagnóstico de SARS-CoV-2 en pacientes con } \\
\text { enfermedad renal con la prueba diagnóstica de uso actual en el país: la RT-PCR.] }\end{array}$ & 100 \\
\hline $\begin{array}{l}\text { Se recomienda: [Considerar el uso de pruebas serológicas en pacientes con enfermedad renal } \\
\text { asintomáticos con historia de contacto con casos sospechosos o confirmados.] }\end{array}$ & 80 \\
\hline $\begin{array}{l}\text { Se recomienda: [Tener en cuenta que los pacientes con enfermedad renal pueden cursar presentaciones } \\
\text { atípicas de la enfermedad COVID-19 debido a condición inmune que disminuye la tormenta de } \\
\text { citoquinas.] }\end{array}$ & 100 \\
\hline $\begin{array}{l}\text { Se recomienda: [Incluir en la definición de paciente sintomático de COVID-19 para paciente con } \\
\text { enfermedad renal síntomas gastrointestinales: diarrea, emesis, náuseas, dolor abdominal.] }\end{array}$ & 98 \\
\hline $\begin{array}{l}\text { Se recomienda: [Incluir la sintomatología gastrointestinal en los procesos de } \\
\text { tamización y clasificación de pacientes.] }\end{array}$ & 100 \\
\hline $\begin{array}{l}\text { Se recomienda: [Incluir como factor de riesgo para mal pronóstico de COVID-19 en paciente con } \\
\text { enfermedad renal, la terapia de reemplazo renal.] }\end{array}$ & 82 \\
\hline $\begin{array}{l}\text { Se recomienda: [Tener en cuenta los mismos factores de riesgo para mal pronóstico de COVID-19 } \\
\text { considerados para la población general: edad mayor a } 60 \text { años y comorbilidades, al menos hasta que haya } \\
\text { nueva evidencia para pacientes con ERC estadio final.] }\end{array}$ & 100 \\
\hline $\begin{array}{l}\text { Se recomienda: [Usar los marcadores para mal pronóstico de COVID-19 propuesto para la población } \\
\text { general según la ACIN, al menos hasta que haya nueva evidencia en pacientes con ERC en estadio } \\
\text { final.] }\end{array}$ & 93 \\
\hline $\begin{array}{l}\text { Se recomienda: [Realizar seguimiento a cambios en los valores de ferritina y de dímero-D, analizando } \\
\text { cada caso de manera independiente, teniendo en cuenta que pacientes en hemodiálisis por defects } \\
\text { podrían tener este marcador incrementado y su resultado podría variar dependiendo de si la medición se } \\
\text { hace antes o después de la diálisis.] }\end{array}$ & 98 \\
\hline $\begin{array}{l}\text { Se recomienda: [Implementar medidas preventivas declaradas en la sección de prevención del presente } \\
\text { documento.] }\end{array}$ & 100 \\
\hline Se recomienda: [Implementar estrategias de seguimiento remoto para evitar complicaciones.] & 100 \\
\hline $\begin{array}{l}\text { Se recomienda: [Implementar estrategias que favorezcan la capacidad de atención en unidades de } \\
\text { diálisis.] }\end{array}$ & 98 \\
\hline Se recomienda que: [Pacientes COVID-19 reciban diálisis de acuerdo col & 100 \\
\hline
\end{tabular}




\section{Continuación ANEXO B}

\begin{tabular}{|c|c|}
\hline Recomendación & $\begin{array}{l}\text { Resultado } \\
\text { consulta } \\
(\%)\end{array}$ \\
\hline $\begin{array}{l}\text { Se recomienda: [Llevar registro de decisiones de reprogramación de diálisis con argumentos de la } \\
\text { decisión.] }\end{array}$ & 98 \\
\hline Se recomienda: [Informar a pacientes y familiares acerca de decisiones del procedimiento.] & 100 \\
\hline $\begin{array}{l}\text { Se recomienda: [Continuar con modalidades instauradas a menos que la condición del paciente } \\
\text { amerite cambios.] }\end{array}$ & 100 \\
\hline $\begin{array}{l}\text { Se recomienda: [Evitar incursionar en nuevas modalidades con las que el personal no está } \\
\text { familiarizado ni capacitado.] }\end{array}$ & 98 \\
\hline $\begin{array}{l}\text { Se recomienda: [Filtrar moléculas de tamaño medio que favorezcan la eliminación de mediadores } \\
\text { inflamatorios.] }\end{array}$ & 89 \\
\hline Se recomienda: [Priorizar la colocación de catéter y acceso vascular en agendas de cirugía.] & 91 \\
\hline $\begin{array}{l}\text { Se recomienda: [Continuar con la práctica habitual de que los pacientes tengan insumos de diálisis para } 15 \\
\text { a } 30 \text { días.] }\end{array}$ & 95 \\
\hline Se recomienda: [Reforzar información de COVID-19 e identificación de signos de alarma.] & 100 \\
\hline Se recomienda: [Realizar seguimiento domiciliario a pacientes con diálisis peritoneal.] & 82 \\
\hline $\begin{array}{l}\text { Se recomienda: [Implementar estrategias de teleasistencia para acompañamiento durante los } \\
\text { procedimientos.] }\end{array}$ & 100 \\
\hline Se recomienda: [Mantener contacto continuo con los pacientes para evitar complicaciones.] & 98 \\
\hline Se recomienda: [Continuar el manejo habitual de líquidos de diálisis peritoneal.] & 100 \\
\hline $\begin{array}{l}\text { Se recomienda: [Utilizar solución clorada en proporción de } 500 \mathrm{mg} / \mathrm{l} \text { durante una hora antes de su } \\
\text { descarte de líquidos en el inodoro.] }\end{array}$ & 95 \\
\hline Se recomienda: [Evitar salpicaduras de gotas al descargar el inodoro.] & 98 \\
\hline $\begin{array}{l}\text { Se recomienda: [Adherirse a las indicaciones de ingreso a UCI sugeridas por la AMCI para paciente } \\
\text { sospechoso o COVID-19, al menos hasta que exista información específica para paciente con ERC.] }\end{array}$ & 100 \\
\hline $\begin{array}{l}\text { Se sugiere: [El uso de herramientas de evaluación de riesgo y pronóstico en pacientes con COVID-19 y } \\
\text { ERC, para orientar la práctica clínica y optimizar la prestación de servicios.] }\end{array}$ & 98 \\
\hline Se sugiere: [Utilizar las escalas NEWS, qSOFA y PNEWS en población infantil con ERC.] & 98 \\
\hline $\begin{array}{l}\text { Se recomienda que: [Cada institución con UCI tenga un protocolo de priorización de admisión de } \\
\text { pacientes con una visión holística y multidisciplinar que permita el concurso y la evaluación conjunta } \\
\text { con las áreas de geriátrica y de cuidado paliativo.] }\end{array}$ & 100 \\
\hline $\begin{array}{l}\text { Se recomienda: [Basar los criterios de priorización en principios éticos de justicia distributiva, equidad, } \\
\text { proporcionalidad, confianza, deber de atención, transparencia, consistencia y responsabilidad.] }\end{array}$ & 100 \\
\hline $\begin{array}{l}\text { Se recomienda: [Considerar en los parámetros de admisión a UCI las condiciones basales del paciente, la } \\
\text { relación del riesgo versus el resultado clínico potencial y el pronóstico del paciente medido } \\
\text { objetivamente.] }\end{array}$ & 100 \\
\hline $\begin{array}{l}\text { Se recomienda: [Tener un comité de supervisión y un registro de la priorización de pacientes y los } \\
\text { argumentos para la decisión.] }\end{array}$ & 100 \\
\hline $\begin{array}{l}\text { Se recomienda: [Informar a pacientes y familiares acerca del protocolo y el proceso de } \\
\text { priorización.] }\end{array}$ & 93 \\
\hline $\begin{array}{l}\text { Se recomienda: [Garantizar el cuidado compasivo de todos los pacientes, incluyendo su adecuado } \\
\text { control de síntomas y la importancia de acompañar sus necesidades psicológicas y emocionales.] }\end{array}$ & 100 \\
\hline $\begin{array}{l}\text { Se sugiere que: [Pacientes con ERC que cursen con enfermedad COVID-19 con indicadores de mal } \\
\text { pronóstico sean consultados acerca de preferencias al final de la vida si su pronóstico no cambiará.] }\end{array}$ & 95 \\
\hline
\end{tabular}




\begin{tabular}{|l|c|}
\multicolumn{1}{c}{ Recomendación } & $\begin{array}{c}\text { Resultado } \\
\text { consulta } \\
\text { (\%) }\end{array}$ \\
\hline $\begin{array}{l}\text { Se sugiere que: [Nefrólogos estén capacitados para consultar a los pacientes acerca de voluntades } \\
\text { anticipadas.] }\end{array}$ & 98 \\
\hline $\begin{array}{l}\text { Se sugiere que: [Voluntades anticipadas de pacientes con ERC y COVID-19 queden documentadas, } \\
\text { preferiblemente con testigo o soporte en video.] }\end{array}$ & 95 \\
\hline $\begin{array}{l}\text { Se recomienda que: [Las unidades renales implementen estrategias de cuidado de salud mental para } \\
\text { pacientes y personal de salud.] }\end{array}$ & 100 \\
\hline $\begin{array}{l}\text { Se recomienda: [Mantener contacto con los pacientes a través de llamadas telefónicas, tele asistencia u } \\
\text { otras herramientas tecnológicas.] }\end{array}$ & 100 \\
\hline $\begin{array}{l}\text { Se recomienda que: [Brindar apoyo psicológico a pacientes y personal de la salud, al menos durante la } \\
\text { epidemia.] }\end{array}$ & 100 \\
\hline Se recomienda: [Promover el autocuidado y el desarrollo de actividades en casa.] & 100 \\
\hline
\end{tabular}




\section{Anexo C. Grupo desarrollador}

Dirección del consenso

Nancy Yomayusa

Comité directivo consenso

Nancy Yomayusa, Gustavo Aroca, Richard Baquero, Erica Yama, Camilo González, Adriana Robayo, Amaury Ariza, Juan Guillermo Vargas, Jorge Rico, Roberto Ramírez, Rodolfo Torres

Comité metodológico Kelly Chacón

Comités de expertos clínicos

\section{Capítulo I: Diálisis}

Coordinadores: Erika Yama, Amaury Ariza.

Erica Yama, Amaury García, Jorge Coronado, Javier Galeano, Luis Barros, Alfonso Brunch Mauricio Sanabria, Jesús Muñoz, Benjamín Wancjer, Juan Carlos Alarcón, Rafael Gómez, Freddy Ardila, Alfonso Bunch, Luis Alfonso Valderrama, Leonardo Hernández, María Inés Gómez, Huber Sánchez, Diego Benavides, Francisco López, Andrés Díaz, Alberto Yunez, Marco Anaya, Huber Sánchez, Mauricio Ruiz.

\section{Capítulo II: Lesión Renal Aguda}

Coordinadores: Camilo González, Juan Guillermo Vargas, Jorge Rico.

Camilo González, Jorge Echeverri, Jorge Rico, Juan Guillermo Vargas, David Ballesteros, Manuel Huérfano, Mauricio Guerrero, Guillermo Pinzón, Greissy Gonzales, Leonardo Marín, Carlos Lozano, Helman Benavides, Alejandra Molano, Andrea Caicedo, Manuel Huérfano, Richard Baquero, Adalberto Peña, Alexandra Lizarazo, Andrés Díaz, David Ballesteros, Diana Vargas, Jhon Serna, Emir Ortiz, Enrique Benavidez, Jorge Pulido, Jorge Mora, María José Vargas, Paula Rodríguez, Kateir Contreras, Mauricio Guerrero, Rodrigo Daza, Sandra Juliana Jiménez, Adriana Robayo, Gabriel Cantor.

\section{Capítulo III: Nefrología Pediátrica: Coordinador: Richard Baquero.}

Natalia Mejía, Jimena Cáceres, Diana Carolina Chacón Jaimes, Ehimy Suarez Barajas, Richard Baquero, Natalia Mejía, Jimena Cáceres, Ehimy Suarez Barajas, Angélica María Calderón Ortiz, Adriana Isabel Meza Martínez, Carolina Lucia Ochoa, Douglas Ramón Villafañe Bermúdez, Zilac Espitaleta, Gustavo Guerrero Tinoco, Martha Isabel Carrascal.

\section{Capítulo IV: Adulto Mayor y Multimorbido:} Coordinador: Roberto Ramírez. Joaquín Rodelo, Héctor Mauricio Cárdenas, Álvaro Mercado, Hernando Altahona, Sandra Castelo, Mercedes Alfaro, Inge Arroyabe, Viviana Raoch, Elizabeth Ardila, Claudia Acosta, Roberto Ramírez, Ignacio Villanueva.

\section{Capítulo V: Trasplante y Enfermedad Glomerular:} Coordinador: Rodolfo Torres.

Camilo Montero, Paola García, Andrés Acevedo, Rodolfo Torres, Gustavo Aroca, Astrid Hernández, Orlando Olivares, Natalia Malaver, Jessica Pinto, Sandra Juliana Jiménez, Gustavo Aroca, Marco Anaya, Sonia Celi.

\section{Capítulo VI: Enfermería Nefrológica \\ Coordinadores: Diana Gayón, Jorge Pérez}

Ingrid Torres, Carolina Pedraza, Natalia Carolina Tobón, Betty Zambrano, Jeniffer Fordon, Liseth Rincón, María Fernanda Pérez, Luisa Fernanda Grajales, Luis Chaparro Quiroz

Equipo técnico-científico multidisciplinar

Geriatría

Héctor Mauricio Cárdenas. Asociación Colombiana de Geriatría

$$
\begin{aligned}
& \text { Nefrogeriatría } \\
& \text { Carlos Guido Musso. Argentina }
\end{aligned}
$$

Cuidado Paliativo

Sandra Liliana Parra, Paola Marcela Ruiz, María Victoria Mera, Gabriela Sarmiento.

\section{Infectología Pediátrica}

Sandra Beltrán

Ministerio de Salud:

Álvaro Burgos 